Portland State University

PDXScholar

5-1997

\title{
Analysis of Rhetorical Organization and Style Patterns in Korean and American Business Fax Letters of Complaint in English
}

Mi Young Park

Portland State University

Follow this and additional works at: https://pdxscholar.library.pdx.edu/open_access_etds

Part of the Applied Linguistics Commons

Let us know how access to this document benefits you.

\section{Recommended Citation}

Park, Mi Young, "Analysis of Rhetorical Organization and Style Patterns in Korean and American Business Fax Letters of Complaint in English" (1997). Dissertations and Theses. Paper 5791.

https://doi.org/10.15760/etd.7662

This Thesis is brought to you for free and open access. It has been accepted for inclusion in Dissertations and Theses by an authorized administrator of PDXScholar. Please contact us if we can make this document more accessible: pdxscholar@pdx.edu. 
THESIS APPROVAL

The abstract and thesis of Mi Young Park for the Master of Arts in TESOL were presented May 8, 1997, and accepted by the thesis committee and the department.

COMMTTTEE APPROVALS: Marjorie Terdal, Chair
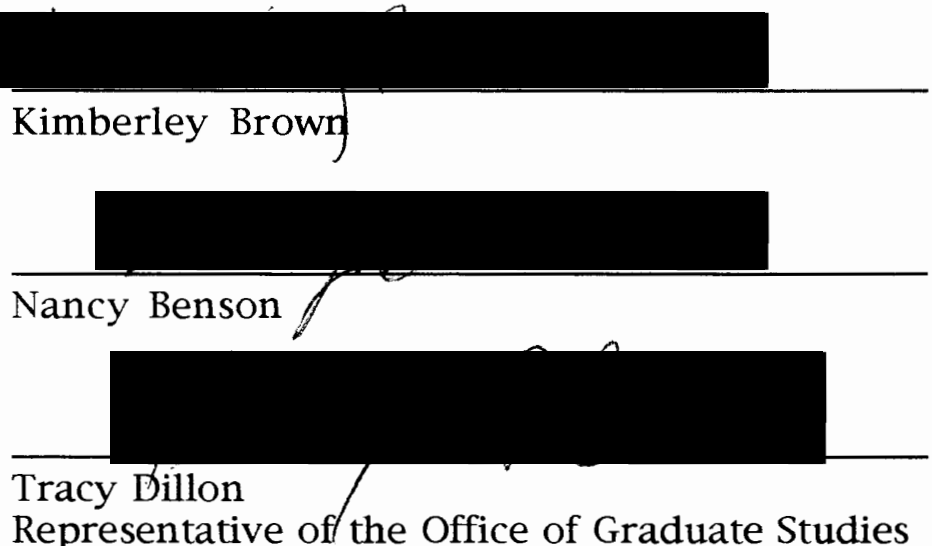

DEPARTMENT APPROVAL:

Marjorie Terdal, Acting Chair

Department of Applied Linguistics

ACCEPTED FOR PORTLAND \$TATE UNIVERSITY BY THE LIBRARY

by

on

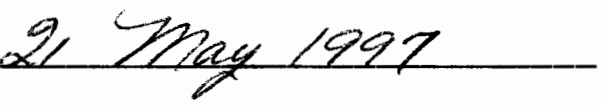




\begin{abstract}
An abstract of the thesis of Mi Young Park for the Master of Arts in TESOL presented May 8, 1997.
\end{abstract}

Title: Analysis of Rhetorical Organization and Style Patterns in Korean and American Business Fax Letters of Complaint in English.

The purpose of this study was to find out if Korean and American business people use different rhetorical patterns in business writing, and if so, how these patterns differ. Specifically, this study examined rhetorical organization and style patterns of Korean and American business letter writing in English to determine differences.

The data used in this study consisted exclusively of fax transmitted business letters of complaint written in English obtained from seven companies in Korea. The sample consisted of seven letters written by American business people and fourteen by Korean business people. They were analyzed according to a predetermined set of coding categories both for organization and style patterns. Organizational patterns were examined by the ways in which the two different groups of writers presented the complaint, relevant information, and requests for action. Style patterns 
were examined by the ways in which the message was delivered and referred to the reader and writer within the two communicative functions of complaint acts and request acts.

From the analysis of American and Korean rhetorical patterns, differences were found within organization and style. Regarding organization of business letters, the American rhetorical pattern was characterized as "direct" or "linear" and the Korean rhetorical pattern as “indirect” or "non-linear." Regarding style patterns, when presenting complaints American styles were consistently implicit; the complaint sources were impersonalized and the complaint message was hedged, yet clear. When requesting action, American styles were explicit and implicit; however, even when American styles were implicit, the message was still clear. On the other hand, Korean styles were not consistent. The complaint sources were more personalized making the complaint act explicit, and the complaint message was also hedged, yet this hedging caused "ambiguity." When requesting action, Korean styles were also explicit and implicit; however, when Korean styles were implicit, it generally led to "ambiguity." 
Dedicated to Amita 


\title{
ANALYSIS OF \\ RHETORICAL ORGANIZATION AND STYLE PATTERNS IN KOREAN AND AMERICAN BUSINESS FAX LETTERS \\ OF COMPLAINT IN ENGLISH
}

\author{
by \\ MI YOUNG PARK
}

A thesis submitted in partial fulfillment of the requirements for the degree of

\author{
MASTER OF ARTS \\ in
}

TESOL

Portland State University

1997 


\section{TABLE OF CONTENTS}

\section{PAGE}

LIST OF TABLES $\ldots \ldots \ldots \ldots$ iii

LIST OF FIGURES $\ldots \ldots \ldots \ldots \ldots \ldots$ iv

\section{CHAPTER}

I INTRODUCTION $\ldots \ldots \ldots \ldots \ldots \ldots \ldots \ldots$

Background and Justification ............. 1

Research Design .............. 5

II REVIEW OF THE LITERATURE ................ . . 9

Organizational Anomalies ............. 9

Contrastive Rhetoric . . . . . . . . . . . 11

Korean Cultural Rhetorical Patterns .......... . 14

Rhetorical Differences in Business Writings

across Cultures ................ 19

Understanding English Business Writing Instruction

in two Cultures: America and Korea . . . . . . . . . 24

Complaints in Cross-cultural Business Discourse . . . . 30

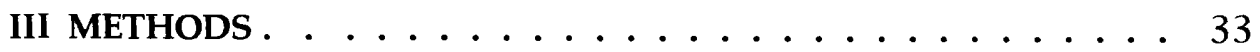

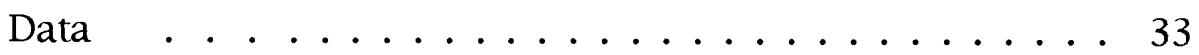

Data Collection ................. . . . 35

Privacy and Confidentiality ............ 37

Data Analysis .................... 37

IV ANALYSIS AND DISCUSSION . . . . . . . . . . . . . 47

Length of Letters . . . . . . . . . . . . . . . . . . . . . . . . . . . . . . . .

The Format .................... 48 
Rhetorical Organizational Patterns . . . . . . . . . 51

Coding of Meaning Components . . . . . . . . . . 51

The Presence of Meaning Components . . . . . . 55

The Sequential Order of Meaning Components . . . 58

Buffers . . . . . . . . . . . . . . 667

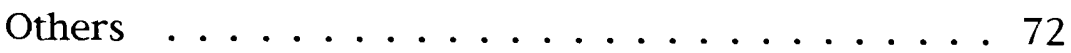

"Lack of Specificity" . . . . . . . . . . . . . 73

Connectives . ............. . . 78

Rhetorical Style Patterns . . . . . . . . . . . . . . . 82

Coding of Rhetorical Strategies $\ldots \ldots$. . . . . 82

Complaint Acts . . . . . . . . . . . . 87

Request Acts . . . . . . . . . . . . . 95

Summary of Rhetorical Style Patterns . . . . . . . 101

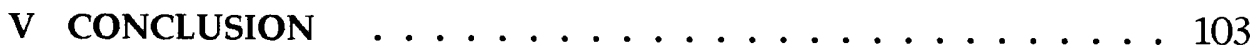

Discussion of Research Questions . . . . . . . . . 103

Conclusions . . . . . . . . . . . . . . . 112

Pedagogical Implications . . . . . . . . . . . . 115

Limitations . . . . . . . . . . . . . . . 118

Suggestions for Further Research _ . . . . . . . . 120

REFERENCES . . . . . . . . . . . . . . . . . . 122

\section{APPENDICES}

A CONSENT FORM IN ENGLISH $\ldots \ldots \ldots \ldots \ldots$

B CONSENT FORM IN KOREAN . . . . . . . . . . 129 


\section{LIST OF TABLES}

TABLE

PAGE

1 Cultural Rhetorical Patterns .............. 19

2 Content of English Business Letter Writing . . . . . . 26

3 Coding Scheme for Organization:

Meaning Components of Business Letters of Complaint . . . 38

4 Rhetorical Strategies of Business Letters of Complaint . . . 42

5 Characteristics of Rhetorical Patterns . . . . . . . . 46

6 Length of Letters . . . . . . . . . . . . . . . . . 47

7-1 Supplementary Lines: American Letters . . . . . . . . . . . 48

7-2 Supplementary Lines: Korean Letters . . . . . . . . . . 49

8 The Presence of Meaning Components . . . . . . . . 56

9 Occurrences of Buffers .............. 69

10-1 Types and Usage of Buffers: American Letters . . . . . . 69

10-2 Types and Usage of Buffers: Korean Letters . . . . . . . . 70

11 Occurrences of "Lack of Specificity" . . . . . . . . . . 74

12 Use of Connectives ................ 79

13 Functional Categories of Hedges Used in Complaint Acts . . 87

14 Rhetorical Strategies for Complaint Sources . . . . . . . 90

15 Functional Categories of Hedges Used in Request Acts . . . . 96

16 Types for Action Requests . . . . . . . . . . . . . 98

17 Summary of Rhetorical Style Patterns . . . . . . . . . 101 


\section{LIST OF FIGURES}

FIGURE

PAGE

1 Robert Kaplan: Cultural Differences in Rhetorical

Patterns ................... 12

2 Illustrating "Moves" ................. 54

3 The Presence of Meaning Components . . . . . . . . 57

4-1 Sequential Order of "Moves": American Letters . . . . . . . 59

4-2a Sequential Order of "Moves": Korean Letters 1-7 . . . . . . 60

4-2b Sequential Order of "Moves": Korean Letters 8-14 . . . . . . 61

5 Model of General "Move" Patterns . . . . . . . . . . . 62

6-1 Rhetorical Strategies: American Letters . . . . . . . . . 84

6-2a Rhetorical Strategies: Korean Letters 1-7 . . . . . . . . . 85

6-2b Rhetorical Strategies: Korean Letters 8-14 . . . . . . . . . 86 


\section{CHAPTER I}

\section{INTRODUCTION}

\section{Background and Justification}

This study presents a contrastive rhetorical pattern analysis of how English is composed for international business complaints in the writings of Korean and American business people.

Increasingly, in Korea, the use of English as a foreign language (EFL) is motivated by very practical concerns, primarily the economic "Globalization" policy of the Korean government since 1995. The goal of this policy is to reinforce the country's economic strength so that Korea can compete with other developed countries economically and politically in the world market. As one way of reinforcing Korea's economic competitiveness in the world market, English for business purposes has become a forefront interest of adult learners because it is the language of international business communication.

Since English is a foreign language to Koreans, this raises the question of whether or not rhetorical "anomalies" in written business English discourse may occur. From the perspective of Teaching English to Speakers of Other Languages (TESOL), the term Business English implies "the existence of a discrete form of language" (Robinson, 1991, p. 97). This 
concept suggests that the use of English in business communication contexts is a shared "work language" by the native speaker (NS) and the non-native speaker (NNS). In relation to the use of English in the business domain, Louhiala-Salminen (1996) presents one important issue: the differentiation between L1 (first language) and L2 (second language) English seems to be fading in cross-cultural business communication settings (p. 40). For example, in business "language," both Korean and American business people may use the same terminology, abbreviations, or acronyms, and the fact that business communication seems to work within the international business community indicates acceptance of L2 strategies; thus, the boundaries between L1 and L2 Business English are becoming less rigid. However, even though boundaries are less rigid, at the rhetorical level differences may occur in organization and style patterns affecting communication. For example, if the NS or NNS's rhetorical expectations are violated, this can detract from the intended message inhibiting effective business English communication.

To examine effective communication, the broad term Business English must be narrowed down, and it is necessary to focus on one particular genre and approach to understand cross-cultural business discourse; this study will focus on the genre of business fax letters in English written by NS and NNS using the contrastive rhetoric approach. First, the genre of business fax letters is used because fax letters are 
increasingly replacing traditional business letters in the international business setting, and these letters have assumed a crucial role in maintaining and promoting relationships in written business discourse. Because fax machines permit instant delivery of documents, business fax letters are often used to resolve urgent business transactions such as complaints or claims. Second, the contrastive rhetoric approach is used for examining cross-cultural communication because it is relevant, raising the question whether or not rhetorical differences occur between crosscultural English business letters.

Contrastive rhetoric (CR) addresses similarities and differences in rhetorical patterns of writing across languages and cultures. In contrasting rhetorical patterns across languages, studies of CR have been influential in illustrating cultural differences in rhetoric, and the influence of L1 cultural rhetorical patterns and norms on the NNS's English writing behavior (Kaplan, 1966, 1972; Hinds, 1987, 1990; Matalene, 1985; Norton, 1987; Liebman, 1988; Hinkel, 1994). One important implication drawn from the assumptions of $C R$ is that what is effective in Korean rhetoric may not be effective in English, and vice versa.

In the academic domain, CR research has facilitated an understanding of rhetorical level "organizational anomalies" in the L2 (English) writings of Korean learners. For example, in English rhetoric, clarity is the norm, and the concept of clarity is linked to linear or direct 
development of the writer's point in organization and style; thus, English rhetoric is considered "direct" or "linear." When a Korean student fails to be specific and relates ideas loosely or indirectly in L2 writing, this seems to be "unrelated" or "disconnected" to the NS reader. However, in Korean rhetoric, the use of indirect forms of writing is valued and making connections is left to the reader (Hinds, 1987; Yum, 1987; Hinkel, 1994); thus, Korean cultural rhetorical patterns are considered "circular" and “indirect."

Although there has been some research regarding Korean L2 writing in an academic setting, there has been very little or no research regarding the assumptions of CR in Korean L2 business writing, and this raises certain questions: Are there any rhetorical differences between the English writings of Korean and American business people? Are there any preferred rhetorical styles and organizational patterns in these business communities? Do the characteristics of Korean L2 writing that researchers have found in the academic setting also apply to the business setting? If these differences exist, do they cause communication difficulties between Korean and American English business discourse? Also, is it possible that Korean business people transfer L1 strategies to L2 writing, and are other cultural/rhetorical principles such as "politeness" or "indirectness" affecting L2 business writing?

Answers to these questions in this line of research have beneficial 
implications for both Korean and American business writers in crosscultural communication contexts in that this study can uncover rhetorical differences that may exist between the two different groups of native and non-native speaking business people. Also, the results of this research can be beneficial not only to L2 writers and learners but to L2 instructors for business purposes.

\section{Research Design}

The major motivation for this study was to apply the assumptions that CR researchers have established in the academic setting to the business setting. The purpose of this study was to find out if Korean and American business people use different rhetorical patterns in business writing, and if so, how these patterns differ. Specifically, this study examined rhetorical organization and style patterns of Korean and American business writing in English to determine differences. This study focused on the genre of business fax letters of complaint and addressed the following specific research questions:

1. In rhetorical organization, are there any differences in the way Korean and American business people organize the business complaint message? If so, how can such differences be characterized? 
2. In rhetorical organization, are there any differences in the way Korean and American business people use connectives? If so, how do the differences affect the organizational pattern?

3. In complaint acts, are there any differences in the way Korean and American business people use rhetorical strategies (lexical hedges, impersonalization of complaint sources, and "intense" adjectives/adverbs)? If so, how do the differences affect the rhetorical style patterns?

4. In request acts, are there any differences in the way Korean and American business people use rhetorical strategies (lexical hedges and types of action requests)? If so, how do the differences affect the rhetorical style patterns?

In answering these questions, it is important to note that unlike most studies in CR that have characterized English rhetorical patterns using style manuals or textbooks (Kachru, 1995, p. 25), this study examined actual business writing because the data consisted exclusively of authentic fax transmitted business letters used for international business in Korean and American companies. Thus, this study would find "live" features of written English business discourse. Also, among several proposed topics of business letters, this study examined only complaints because they are an unavoidable feature of business discourse. 
The general design of this study was a "categorical" written discourse analysis because the analysis followed predetermined sets of coding schemes (Nunan, 1992). The data analysis examined and contrasted rhetorical organization and style patterns between Korean and American business letter writings in English. In this paper the word "American" is used to refer to the United States.

For organization, the study considered basic "meaning components" of business letters of complaint which were: (I) Identification of problem, (II) Relevant information, (III) Request for action desired, (IV) Topic shift, and (V) Buffer. The presence and sequential order of the meaning components were considered as determining factors of "direct" or "indirect" development in organization. At the quantitative level, the presence of meaning components was determined by the number of words. The sequential order was analyzed by "move" patterns (Swales \& Najjar, 1987). In addition, the occurrences of "Lack of Specificity" within the meaning components were counted and analyzed. Also, the use of connectives was examined because appropriately used connectives help the smooth transition of ideas, and lead readers to follow the writer's logic.

For style, this study considered four rhetorical strategies that might influence the "implicit" and "explicit" modes of the message. They were:

(1) Lexical hedges, (2) Impersonalization of complaint sources, (3) "Intense" adverbs/adjectives, and (4) Types of action requests. These 
four rhetorical strategies were analyzed according to their communicative functions, which were complaint acts or request acts.

To develop the coding schemes for this study, Connor, David, and Rycker's model (1995) was primarily adapted, and small sections were drawn from various research projects of $\mathrm{CR}$, linguistics and business communications (Halliday \& Hasan, 1976; Ewald \& Stine, 1983; Swales \& Najjar, 1987; Murphy \& Hildebrandt, 1988; Hatch, 1992; Kim \& Bresnahan, 1994; Salager-Meyer, 1994; Bovée \& Thill, 1995; Virtanen, 1995; Harcourt, Krizan, \& Merrier, 1996).

In Chapter 2, this study provides a review of CR literature focusing on Korean learner's "organizational anomalies" in L2 writing and Korean cultural rhetorical patterns; also, Chapter 2 includes discussion of research findings on business writing across cultures, comparison of American and Korean business writing manuals, and finally an explanation of complaints as communicative events in cross-cultural business contexts. The method and coding scheme of the data are discussed in detail in Chapter 3. Chapters 4 and 5 include coding procedures, results, discussion of the research questions, and implications of the study. 


\section{CHAPTER I I}

\section{REVIEW OF THE LITERATURE}

This chapter consists of six sections. The first two sections discuss "organizational anomalies" in English (L2) writings of Korean learners, and presents contrastive rhetoric as an approach to understand the nature of L2 learners' writing behavior. The third section provides an overview of contrastive rhetoric research, particularly related to Korean cultural rhetorical patterns, and the fourth section reviews research on business writing across cultures and discusses the differences in rhetorical approaches. The fifth section provides a comparison of business writing manuals between the U.S. and Korea to understand the writing practices of Korean and American business people in English. Finally, the sixth section shows complaints as communicative events in cross-cultural business contexts.

\section{Organizational Anomalies}

In English writing, Korean learners have shown some organizational "anomalies" on the rhetorical level beyond linguistic difficulties at the sentence level (e.g., grammar, syntax, and vocabulary). Native speaker (NS) 
instructors often comment that "The material is all here, but it seems somehow out of focus," or "lacks organization," or "lacks cohesion" (examples cited in Kaplan, 1966, p. 3). These comments pinpoint Korean learners' difficulties in expressing their thoughts clearly and effectively, from an American perspective, in L2 written discourse and question the adequacy of their L2 proficiency.

In this regard, Kaplan (1972) gives the following example of a Korean learner's L2 composition (p. 47):

Kaplan's example of

a Korean learner's writing:

Definition of College Education

College is an institution of an higher learning that gives degrees. All of us needed culture and education in life, if no education to us, we should to go living hell.

One of the greatest causes that while other animals have remained as they first man along has made such rapid progress is has learned about civilization.

The improvement of the highest civilization is in order to education up-to-date. So college education is very important thing which we don't need mention about it.
My interpretation of

“anomalies" seen by NS:

- . . . . topic to be discussed,

- . - . - no relation yet

- . - . - still no mention of college education, but mention of college

general statement
about civilization,
has little to do with
topic.

- . - - general statement about civilization and education mentions college education but as an obvious concept that needs not be discussed. 
It is important to note that while the learner has grammatical errors, the more serious problem is his L2 organizational patterns. In English writing, the NS expects a clear statement of the thesis at the beginning, and the development of supporting ideas in a direct manner. Disregarding the grammatical errors, there is no topic sentence at all in the above writing, so "the text seems to ramble quite freely from one idea to the next" (Norton, 1987 , p. 7). In other words, Norton suggests that even without grammatical errors, "sentences of Korean students still remain incoherent and unorganized" (p. 7). Regarding this rambling style, Kaplan argues that in "Oriental" writing the development of the paragraph is "turning and turning in a widening gyre" and the subject is never looked at directly (Kaplan, 1972, p. 46). Such a development seems not to follow the same logic as "English," and it creates awkward and indirect impressions.

\section{Contrastive Rhetoric}

Contrastive rhetoric (CR), the study of differences in rhetorical patterns of writing across languages and cultures, is one approach to understanding Korean learners' "anomalies" in L2 written discourse. The first attempt at rhetorical analysis was done by Kaplan at the discourse level. In his original proposal (1966), Kaplan applied the contrastive analysis of rhetoric across languages, and graphically represented five cultural rhetorical patterns: 


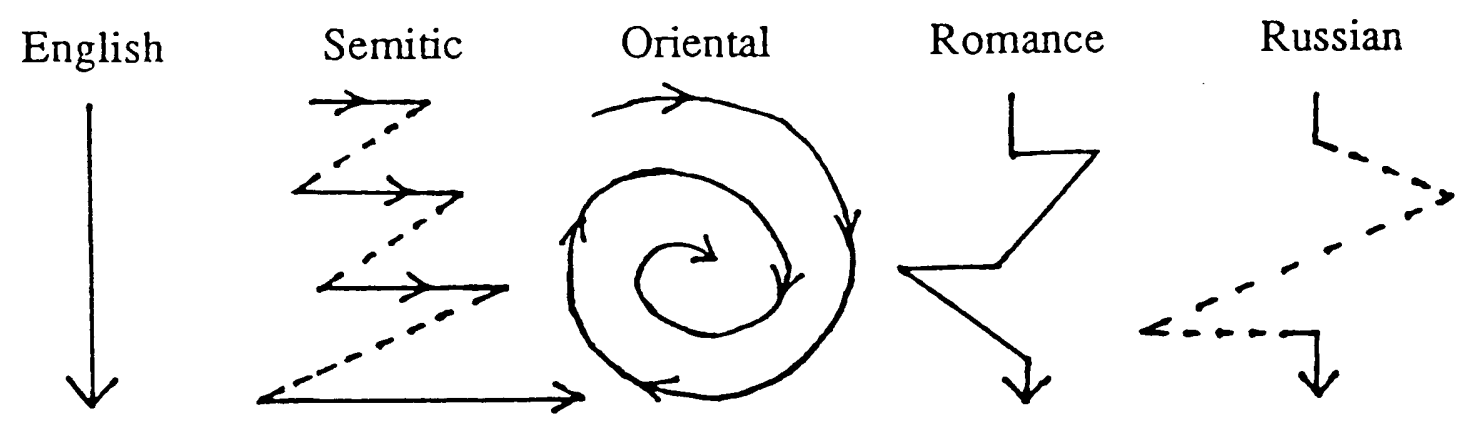

Figure 1. Robert Kaplan: Cultural Differences in Rhetorical Patterns

English rhetoric is direct or linear; "Oriental" rhetoric is indirect or circular; Semitic rhetoric is parallel; and Romance and Russian rhetorics are more digressive. These rhetorical patterns represent Kaplan's original hypothesis that rhetoric is not universal, and that "each language has a paragraph order unique to itself" (p. 14).

According to Kaplan (1966), logic is the basis of rhetoric and it is evolved out of culture (p. 2). In his study, rhetoric is the organizational pattern; in other words, the method of organizing syntactic units into larger patterns (Kaplan, 1967, p. 15). According to Bar-Lev (1986), "different languages have different rhetorical norms, representing different ways of organizing ideas" (p. 236). If rhetoric varies from culture to culture, it is important that instructors of writing consider the learners' first language (L1) cultural background to understand the nature of organizational "anomalies" in the learners' L2 writing. 
Although Kaplan's study of CR addresses discourse level "anomalies" in terms of the relationship between language and culture, it is also important to notice that Kaplan's characterization of five cultural rhetorical patterns tends to be ethnocentric because it was essentially based on the NS's rhetorical norm (Severino, 1993; Kachru, 1995). Also, Kaplan's methodology lacks "triangulation" because he mainly used his intuitions and unsystematic analysis of language data (Liebman, 1988). Finally, Kaplan's contrastive analysis views the transfer of L1 rhetorical patterns to L2 writing negatively, so L1 transfer is considered an "error." In Martin's study (1991), this is criticized as a "formalistic view" because Kaplan examined strictly formal differences across languages. However, Martin's review of studies of CR acknowledges that recent studies of CR have promoted an "interactive view" by considering that "values, ideologies and norms of discourse communities play an important part in shaping written discourse" (p. 4). When L2 learners use their native rhetoric within the second language, the native rhetoric itself should not be considered wrong; instead, it should be viewed as inappropriate use of rhetoric with the L2. In other words, L1 rhetoric is not functional within L2.

One of the most controversial aspects of rhetorical differences in L2 writing is whether to look at "anomalies" in L2 writing as being influenced by the L1 cultural rhetorical patterns or as a feature of developmental factors in L2 learning. In relation to developmental factors, Mohan and Lo 
(1985) claim that the L2 learner's organizational problems lie in educational systems, not in the influence of L1 cultural rhetorical patterns. They argue that sentence-level (e.g., grammar, syntax, and vocabulary) oriented instruction causes the L2 learner's inability to organize texts on a discourse level. Educational systems are also a part of the culture, and the culture determines what is important in L2 instruction. And in many Asian countries such as China, Japan, and Korea, sentence-level accuracy is emphasized over organizational discourse. However, even those considered proficient L2 language users still reveal organizational "anomalies" in their L2 writing. Therefore, the NNS's organizational difficulties can not be wholly seen as L2 developmental factors.

Another controversial aspect of $\mathrm{CR}$ is whether or not rhetorical patterns are culture-specific or universal. Some research (Shishin, 1985; Mohan \& Lo, 1985) suggests that cultures are not limited to only one rhetorical pattern, and that both "linear" and "non-linear" patterns can occur within one culture. However, much research (Matalene, 1985; Bar-Lev, 1986; Norton, 1987; Hinkel, 1994) provides evidence that one rhetorical style in a given culture usually takes predominance over others, and cultural norms and values influence the L2 learner's writing behavior.

\section{Korean Cultural Rhetorical Patterns}

Although current research suggests Kaplan's original hypothesis is 
limited, his characterization regarding Korean cultural patterns is not wholly erroneous. Kaplan's research has inspired a considerable amount of further research on CR; however, most sample texts written by native Korean speakers have been dealt with and included in "Asian" or "Oriental" rhetorical patterns. Three major studies (Norton, 1987; Hinds, 1987, 1990) have been conducted in-depth about Korean cultural rhetorical patterns. Norton's (1987) and Hinds' (1990) studies attempt to understand the rhetorical logic of Korean learners in L2 writing. Both studies examine differences in rhetorical (organizational) patterns between English and Korean, and agree that the English rhetorical pattern is deductive although their interpretations of Korean rhetorical patterns are slightly different: while Norton's study identifies Korean rhetorical patterns as inductive, Hinds' study redefines them as "quasi-inductive."

Norton's study began with his teaching experiences in Korea. After three years teaching in Korea, Norton became perplexed by the inability of his Korean students to communicate their thoughts to him in written English (p. 3) and questioned that "something” wasn't being communicated:

what can be communicated to members of your own culture via written language, are somehow lost on the cold surface of a page written for someone of a different culture. (p. 5)

In order to characterize culturally based differences in writing patterns between Korean and English, he examined eighteen basic types of 
expository essays selected from both Korean and American cultures. The essay topics were nature, philosophy, and customs. Using discourse analysis, each idea in an essay was compared to every other idea in the same essay, and the relationship of the ideas was identified. One of the major findings of Norton's study is that deductive organizational patterns (having the thesis statement in the beginning) are dominant in English writing, while inductive organizational patterns (having the thesis statement in the end) are dominant in Korean writing (p. 13).

In Hinds' study (1990), this Korean rhetorical pattern was presented as “delayed introduction of purpose" (p. 98). Hinds' cross-cultural study compared the rhetorical structures of five cultures: English, Japanese, Korean, Chinese, and Thai. The result of his study shows that each culture has "a style of writing that is respected and processed effectively by native speakers of each language" (p. 93): in English the deductive way of writing is typically expected by the reader; however, in the four Asian languages, "the purpose of the article is not made at the beginning but at the end of the article" (p. 98). In his conclusion, Hinds avoids dichotomous distinctions between deductive rhetoric and inductive rhetoric. Many English readers tend to see the rhetorical patterns of these Asian languages as inductive because they are different from deductive. Hinds argues that this is not appropriate for these Asian languages; just because they are not deductive does not mean they are inductive. Thus, Hinds calls these Asian rhetorical 
patterns "quasi-inductive."

Both Norton's and Hinds' studies help explain the miscommunication problems between NS instructors and Korean learners. Native-speaking instructors expect that L2 learner's writing will be organized according to a deductive pattern. If "the introduction of the purpose of the writing" is delayed, it could be difficult to connect general ideas to the specific purpose, so it seems to be unrelated or disconnected. Therefore, when the topic sentence appears at the end, the reader may have lost the relationships to correlate ideas. Pointing out these differences in organizational patterns is also useful for Korean learners to help them express themselves in L2 writing in a way that is more understandable to the native speakers; otherwise, the relationship between ideas is likely to be lost in written discourse communication.

The following observation by Yum (1987) about the aspects of communication applies equally well to an understanding of culturally different expectations in writing:

North American communication very often centers on the sender, and until recently the linear, one-way model from sender to receiver was the prevailing model of communication. Much emphasis has been placed on how senders can formulate better messages, improve source credibility, polish their delivery skills, and so forth. In contrast, the emphasis in East Asia has always been on listening and interpretation. (p. 83)

In Hinds' study (1987), the culturally different expectations in written discourse are presented as "listener/reader responsibility" vs. 
"speaker/writer responsibility." In English, it is the speaker/writer's responsibility to make the text understood; in East Asian languages, the responsibility falls on the listener/reader. In discussing "unity" in organization from language to language, Hinds argues that unity is important in English rhetoric because English readers expect the writer to provide "landmarks" and appropriate "transition statements" so that the reader can follow the writer's logic. On the other hand, in Japanese, Korean, and Chinese, the specific "landmarks" may be absent or the "transition statement" may be more subtle since the writer assumes that the reader is able to interpret implicit meaning (p. 146).

To sum up Korean cultural rhetorical patterns, interestingly the results of the three studies support Kaplan's original "Oriental" cultural rhetorical patterns: Korean cultural rhetorical patterns are more circular and indirect. This assumption indicates what is effective in Korean may not be effective in English rhetoric because culturally-preferred aspects such as deductiveness and inductiveness, directness and indirectness, and writer responsibility and reader responsibility all affect rhetorical patterns. Based on the findings of CR research, Table 1 illustrates differences in cultural rhetorical patterns between English and Korean: 
Table 1.

Cultural Rhetorical Patterns

\begin{tabular}{|c|c|}
\hline English & Korean \\
\hline 1. Linear or Direct & Circular or Indirect \\
\hline $\begin{array}{l}\text { Narrow topic or controlling } \\
\text { ideas are immediately established; } \\
\text { paragraphs develop linearly, } \\
\text { and all new information must } \\
\text { be relevant to the topic. }\end{array}$ & $\begin{array}{l}\text { General theme established; } \\
\text { theme is restated in different } \\
\text { perspectives, though not } \\
\text { always stated directly, but } \\
\text { loosely related to the topic. }\end{array}$ \\
\hline 2. Deductive development & $\begin{array}{l}\text { Inductive or Quasi-inductive } \\
\text { development }\end{array}$ \\
\hline $\begin{array}{l}\text { The statement of purpose } \\
\text { is immediately stated, and } \\
\text { relevant information is followed } \\
\text { in a tightly related manner; } \\
\text { argument develops in a specific } \\
\text { manner. }\end{array}$ & $\begin{array}{l}\text { The statement of purpose } \\
\text { is delayed until the end of } \\
\text { the paper, and relevant } \\
\text { information exists, but is } \\
\text { loosely related; argument } \\
\text { remains general. }\end{array}$ \\
\hline 3. Writer responsibility & Reader responsibility \\
\hline $\begin{array}{l}\text { Emphasis is on clarity and the } \\
\text { writer's presentation; writer's } \\
\text { intention is explicitly stated. }\end{array}$ & $\begin{array}{l}\text { Emphasis is on how the reader } \\
\text { interprets the text; } \\
\text { writer's intention is implied. }\end{array}$ \\
\hline
\end{tabular}

\section{Rhetorical Differences in Business Writing across Cultures}

From a pedagogic perspective, the notion of $C R$ has practical

implications for teaching L2 writing for business purposes because it suggests that the business writer's native cultural rhetorical patterns and norms influence the way writers organize their texts in L2 business writing and this may "violate the expectations of the native reader" (Kaplan, 1966, p. 4). Just as miscommunication occurs between NS instructors and L2 learners in academic writing, so also communication breakdown may occur 
between NS readers and L2 business writers because they may have different culturally-based assumptions about English business writing. Jenkins and Hinds' study (1987) illustrates that differences in conventions and styles of business letter writing have the potential to cause communication breakdowns in the business setting. Based on textbook analysis of business writing in different languages, they examine the writer's and reader's cultural assumptions about organization and content in the "ritualized format" of business letters across three countries: America, France, and Japan. The major findings are: American business letters are reader oriented, French business letters are writer oriented, and Japanese business letters are oriented to the relationship between the writer and reader (p. 327). This means that each culture has different orientations in business communication. Although the function of the business letter does not differ across cultures, clearly its rhetorical orientation does (p. 342). This suggests that effective business letters written in English may not be seen as effective to French or Japanese readers.

Varner's study (1988) also examines American and French business correspondence in the areas of format, organization, tone, and style based on textbooks. The major finding of this study relates to writing principles in the two cultures: (1) American letters have a more action-oriented format, which uses concrete style with many examples; and (2) French 
letters have a more theory-oriented format, which uses abstract writing style without examples (p. 59). Regarding this difference between American and French writing, Varner argues that Americans are "pragmatists" and the French are "theoreticians" (p. 59).

Although in both studies business letter textbooks are used, and usually idealized models are presented, their studies illustrate cultural rhetorical differences in the domain of business letter writing. In reality, however, business letters may include different rhetorical styles and patterns of organization, even if members of different cultures write in the same language. Particularly in the international business setting, English is commonly used as an international language. This poses an important question: is discourse style and organization of L2 business writing culturespecific or universal?

Connor's study (1988) shows cultural differences in written communication patterns in English between Americans and Japanese. Connor employed a case study to compare the organizational structure and the argument development pattern of business reports, and in a comparison of two groups of business correspondence written in English by an American manager and a Japanese manager, the surface linguistic features such as syntax and cohesion appeared similar between the two cultures (p. 61); however, the communication patterns such as organization and argument structure appeared to be different. In organizational patterns, 
information in the American manager's reports was presented coherently and related tightly to the subject, while information in the Japanese manager's reports was often not essential and irrelevant (p. 66); in the development of argument, the American manager used a Westernpreferred, direct and linear pattern, while the Japanese manager used a Japanese-preferred, indirect form of argument (p. 67).

The results of Connor's study show that even though English is used as a common language in the business discourse community, NS business people and L2 business people use different rhetorical approaches, and these differences can lead to communication breakdowns in L2 business writing. This also suggests English rhetorical conventions and norms are not naturally accepted in L2 business writings of NNS, especially in EFL situations like Japan and Korea. Therefore, without understanding the culturally different rhetorical approaches of L2 business people, NS readers may not be able to communicate effectively with them in written English business communication.

Along the same line, Sims and Guice's study (1992), presented from the NS reader's perspective, points out that L2 business people also need to understand the NS reader's cultural expectation to assure effective communication in written English. Their study compared a corpus of inquiry letters written by NSs and NNSs of English, and attempted to identify what factors beyond fluency in a language affect communication. Their 
major findings are: (1) the NNSs' letters significantly deviated from the NS reader's expectations and from standard U.S. business communication practices in format, tone, and information in the letters (p. 36); and (2) the factors that affect communication between native and non-native speakers are knowledge of both business communication practices and cultural expectations of other countries (p. 38). This means the assumption that international business communities share rhetorical styles and patterns because they use the common language, English, is misleading because of the differences between L2 written discourse and L1 rhetorical expectations.

Similarly, Scott and Green's study (1992) points out that even though they use the same language, the U.K. and U.S. were different in rhetorical organizational patterns in business writing disciplines. For example, in the use of English in organizing "bad-news" letters, the study shows that most business letters written in the U.K. convey the message directly and explicitly compared to those written in the U.S. (p. 19).

To conclude, Sims and Guice (1992) effectively argue that in order to understand English business communication in other cultures, both NS and L2 business people should understand different cultural expectations and how English business communication is taught in other countries (p. 37). This suggests that, for example, if American and Korean business people are to communicate with each other effectively in L2 written discourse, both 
need to understand each other's cultural rhetorical patterns and the instructional pedagogy in both cultures.

\section{Understanding English Business Writing Instruction in Two Cultures: America and Korea}

In order to understand the writing practices of Korean and American business writers in English, it is important to examine how English business writing is taught in both cultures.

In English business writing, Korean textbook writers have accepted the NS's models of business writing without distinguishing the difference between British and American standards. For Korean learners, both represent English models, and are thus considered the same. Also, although Korean L2 writers attempt to follow standard models, in reality they are not always successful in duplicating the models. In order to understand how business writers of different cultures are taught to use the common language, English, it is important to look at textbooks and handbooks of English business writing presently available.

In America, generally two types of business writing manuals are prevalent: the first type includes comprehensive discussions and examples of business communication (both written and oral forms) in texts such as

(1)Business Communication Today, 4th ed., (Bovée \& Thill, 1995) and

(2)Business Communication, 3rd ed., (Harcourt, Krizan, \& Merrier, 1996); 
the second type focuses only on business writing (letters, memos, reports, proposals, etc.) in texts such as (3)The Elements of Business Writing (Blake \& Bly, 1991), and (4)Effective Business Writing (Piotrowski, 1996).

In Korea, on the other hand, manuals focusing on English business communication perspectives, both written and oral, are rare, and in most cases the emphasis is on business letter writing from the foreign trade perspective such as (1)Trade English (Kim, 1993), (2)Trade English (Kong \& Jeon, 1996), (3)Practical English Correspondence for Foreign Trade (Yoon, 1991), and (4)Introduction to Trade English (Nakamura, 1996). Therefore, other written discourse forms such as memos, reports, or proposals are not commonly dealt with in these books. In addition, terms such as "Trade English," "Business English," and "English Business Communication” are often used interchangeably to mean English business letter writing. Among the four Korean references above, Kim (1) and Kong and Jeon (2) are currently used as textbooks in two Korean universities. Only the Kong and Jeon text is written in English and the other three are in Korean with examples of model English letters.

It is important to note that Nakamura (4) is translated from Japanese into Korean. In Korea the translation of Japanese texts is not unusual, and this factor indicates that while accepting Western models of English business-writing, Korean instruction may also include other EFL culture's interpretations of English business writing. In other words, there are three 
models of English business writing: British, American, and translated Japanese. Unfortunately, Korean education does not differentiate between these models. Because of this, Korean learners are often confused by inconsistency in the development of rhetorical strategies.

Table 2 compares and summarizes the content of English business writing manuals from two cultures, American and Korean. Because American texts consistently include a broader base of information in both written and oral forms, this examination includes only sections dealing specifically with business letter writing. The reference numbers in Table 2 correspond with the parenthetical number references in the American and Korean texts mentioned above:

Table 2.

\section{Content of English Business Letter Writing}

Content

\section{American References}

$(1)(2)(3)(4)$

1. General Principles

2. Format (Layout)

3. Organization

4. Style and/or Tone

5. Foreign Trade Terms \& Useful Expressions

6. Mechanics (Punctuation, Abbreviation, Capitalization, etc.)

7. Intercultural Communication
Korean

References

(1)(2) (3)(4)

Keys: $+=$ presence, $-=$ absence 
American manuals generally include more diverse content than Korean manuals, and the only element completely missing in American texts is Foreign Trade Terms and Useful Expressions. By contrast, these elements constitute the major part of Korean manuals. Most Korean business writing manuals put emphasis on the use of special trade terms (e.g., "quotation," “invoice," “delivery terms”) and expressions are translated into English after giving detailed grammatical explanations in Korean. Accordingly, examples and exercises are limited to correctness at sentence-level composition (e.g., grammar, syntax, vocabulary), and discourse level strategies such as style, tone and organizational pattern are usually ignored in Korean texts. Furthermore, the process of writing, including pre-writing, revising or re-writing is minimized or ignored, and limited to editing. For example, in American texts a typical exercise offers learners a hypothetical situation and asks them to compose a business letter responding to that situation. On the other hand, Korean texts rely on models and rarely contain practical exercises.

Compared to Korean texts, American texts put emphasis on organization and style in business letter writing. The criteria for a wellorganized message are related to clarity, unity, coherence, and logic. Also, when discussing the order of idea presentation, the writer's intent and situational context are considered important factors in deciding on a direct (deductive) or indirect (inductive) rhetorical approach. Formulation of 
style is also based on situational context and the writer's concern about business relationships. Accordingly, examples and exercises in the manuals require re-writing or revising to create the desired "effectiveness" in written business communication. Even though these discourse level strategies and approaches are prominent characteristics of American texts, fundamentals of grammar, word usage, and mechanics are also considered important factors to enhance the clarity of the message and the writer's expertise, credibility, and professionalism. Interestingly, in Korean manuals, while sentence level accuracy is emphasized, discourse strategies and correct punctuation usage are merely implied.

In regard to general principles of English business letter writing, Korean texts apply the same concepts of the 5Cs (Conciseness, Courtesy, Clarity, Correctness, and Completeness), but they differ from American textbooks in that they spend less time discussing specific examples of subjects like paragraphing, organization, style, and tone within the context of an example letter; instead, they present sentence level examples with no business letter context.

Also, in American manuals, audience-awareness is emphasized in the domain of business letter writing, with issues of tone and style focusing on the audience and culture. It is also important to note that intercultural communication perspectives are discussed thoroughly only in American texts. 
Overall, the two cultures share theoretically common rules in English business letter writing: 1) be clear, 2) be specific and use concrete terms, and 3) arrange information in a logical sequence. However, in approach they display differences. American manuals tend to approach business writing at the discourse level; therefore, all elements of the writing process such as planning for organization, pre-writing, and re-writing to suit the purpose of the letter are explicitly discussed in most manuals. On the other hand, in Korean manuals detailed grammatical explanations, usage of certain syntactic patterns and useful expressions are emphasized, and a literal translation approach from L1 (Korean) to L2 (English) at the sentence level is mainly used. Accordingly, exercises providing discourse level strategies to enhance organization and formulate appropriate style and tone are ignored. Considering the EFL situation of Korea, emphasis on sentence level accuracy is necessary, but not to the exclusion of discourse level proficiency. In the cross-cultural business context, instruction that is solely sentence level oriented creates "unbalanced" letter writing strategies, and can cause Korean business people to have difficulties in developing clear, communicative rhetorical strategies formulating "effectiveness" in L2 written communication.

This comparison illustrates that although these two cultures have similar principles regarding English business letter writing, the different way in which these principles are presented pedagogically is significant in 
that it can create different rhetorical approaches between American and Korean business letter writers.

\section{Complaints in Cross-cultural Business Discourse}

One type of written business communication is the complaint letter. A complaint is a specific communicative event which involves a statement about a problem caused by something that someone else did or did not do in business. According to Hatch (1992), complaint patterns are influenced by the social need to maintain good relationships (p. 142). That is, complaint events in cross-cultural business settings should consider the other culture's conventions of business writing in English and culturally different reader perspectives.

According to handbooks in both American and Korean cultures, business complaints are structured communicative events which follow formally established patterns. Complaints in business letters typically contain three sequentially ordered components: (1) identification of the problem, (2) explanatory information about the causes and effects of the problem, and (3) requests for action in order to solve or improve the problem. In addition, while American handbooks suggest an optimistic closing or "buffer" to establish goodwill in business relationships, Korean handbooks have no discussion about "buffers." Following the direct pattern above seems relatively easy for American writers in English business 
complaint discourse because this pattern is linear and follows their L1 cultural rhetorical pattern. Where Korean L2 business writers are concerned, these patterns are not natural because Korean L1 cultural rhetorical patterns tend to be indirect or circular.

Structuring "effective" complaints in L2 writing requires cultural awareness as well as language awareness. Although the message is negative, complaints in business discourse should be persuasive and polite to culturally different readers. To be persuasive and polite, the business writer should organize and develop ideas according to the same patterns used in the reader's natural thought processes (Plung, 1980, p. 45). Concerning patterns of information processing in business communication, Kenna and Lacy (1995) suggest that Americans tend to think in a logical, sequential order and put an emphasis on factual analysis, while Koreans tend to be more emotion-driven than Americans, and more sensitive to the personal tone of the message rather than facts and numbers (pp. 16-17).

With regard to errors and criticism, Kenna and Lacy (1995) also note that: (1) while open discussion of errors in business transactions and criticism of performance are tolerated by Americans, such discussion and criticism are not readily tolerated by Koreans; and (2) while Americans view criticism as objective and differentiate criticism of a person from criticism of that person's action, Koreans view criticism as personal and "face-threatening," and this can impede "initiative" and information flow 
(pp. 14-15). Also, Hatch (1992) explains that because complaint events include concerns with "face-threatening acts," they contain stylistic elements such as hedges and impersonalization of complaint sources (complainer and complainee). In business letter writing, these rhetorical strategies are purposely used for specific reasons such as politeness and maintaining good business relationships. Even though the use of rhetorical strategies for "saving face" and politeness seems to be universal, the extent to which these strategies are used differs between cultures (Brown \& Levinson, 1987; Yum, 1988; Hagge \& Kostelnick, 1989; Maier, 1992).

Cultural traits such as direct organization and objective attitudes toward criticism (American) versus indirect organization and personal attitudes (Korean) suggest that Americans tend to use logical strategies, while Koreans tend to use emotional strategies in written business discourse. Such cultural differences can lead to breakdowns in communication between the reader and the writer because they use different rhetorical approaches as well as linguistic strategies in handling complaints. 


\section{CHAPTER III}

\section{METHODS}

The nature of this study was a contrastive rhetorical pattern analysis of how English was composed in the writings of Korean and American business people. In this regard, this study employed what Nunan (1992) called a "categorical" written discourse analysis. Because the analysis followed a predetermined set of categories of organizational patterns and styles, it was not "interpretative."

A total of twenty-one fax letters of complaint from international businesses served as the sample of convenience for rhetorical pattern analysis. The data analysis covered organization and style of rhetorical patterns in the letters. For the analysis of organizational patterns, the study adapted primarily Connor, David, and Rycker's model (1995) and adapted small sections from various sources (Ewald \& Stine, 1983; Swales \& Najjar, 1987; Murphy \& Hildebrandt, 1988; Bovée \& Thill, 1995; Virtanen, 1995;

Harcourt, Krizan, \& Merrier, 1996); for rhetorical styles, sections from various research projects (Halliday \& Hasan, 1976; Hatch, 1992; Kim \& Bresnahan, 1994; Salager-Meyer, 1994) were adapted. 
Data

The data consisted exclusively of fax transmitted business letters of complaint written in English. The following criteria applied to selecting the data:

1. Authenticity

All of the data in this study were authentic; they were actually used for international business in Korean and American companies.

2. Mode of communication

Due to the development of technology in communications, faxing has become a common medium of written communication in business settings. Considering the purposes and situations of composing texts, fax transmitted texts might have different characteristics of business discourse from those posted or E-mailed. In order to limit the scope of research, this study was solely based on fax transmitted business discourse.

\section{Genre}

The forms of business discourse through fax communication include letters, reports, memos, notes, etc., either hand-written or type-written. In the general business environment, hand-written or hand-scribbled messages are instantaneous and informal since they are written within a short time with less consideration of communicative situations and tactics. This means the characterization of the hand-written message is closer to that of notes rather than that of letters. Due to these factors, the only form 
of business discourse used in this study was letters. A crucial requirement of business letters is that the fax message must have specific identification of the sender and the recipient; if not, it may be defined as memoranda or memo (e.g., attention: all US dealers/from: public relations). For this study, business fax letters were defined in terms of the following criteria adopted from Yli-Jokipii's characterization of business letters (1991, p. 66):

1) must be a type-written message.

2) must have a date.

3) the recipient must be identified.

4) the sender must be specified in the form of a signature.

4. Topic

Among the various topics of business letters, the study looked at only letters of complaint, and the actual communicative situations in which the data were written varied from small problems to serious claims. The study defined complaint as a communicative event that involved a statement about problems, and the problems were caused by something that someone else did or did not do in business. The communicative event could involve two parties (a complainer and a complainee) or include a third party.

\section{Data Collection}

The data were obtained from seven companies in Korea: six Korean companies and one French company. Among the seven, one company was 
located in Changwon and the others were located in Seoul. The markets these businesses included were electronics, engineering, food, jewelry, shipping, importing and exporting. Also, the size of the participating companies varied from a major corporation to a small, privately owned distributorship. English was the major language used in written discourse in these international businesses.

A total of twenty-one letters of complaint served as the sample of convenience for this study. The gathered data were divided into two groups representing two business writing communities: Korean business community $(\mathrm{KBC})$ and American business community ( $\mathrm{ABC}$ ). Usually companies kept "incoming" and "outgoing" business correspondence files; therefore, letters of complaint written by Americans were from "incoming" files and those written by Koreans came from "outgoing" files of the Korean companies. Also, some of the Korean data came from the "incoming" files of the participating French company.

$\mathrm{KBC}$ consisted of fourteen letters of complaint between Korean companies and companies of other cities and countries such as Hong Kong, America, New Zealand, and France. While one letter was written in December, 1991, the bulk of the data were written between December, 1995, and December, 1996. The data were written by eleven different Korean business people. Two native speaker informants reviewed the data, and excluded data both agreed were written by native speakers of American 
English. The authors' positions at the companies varied from company representative to mid-level working manager.

$\mathrm{ABC}$ consisted of seven letters of complaint, solely between American companies and Korean companies. The data were written by seven American business people between December, 1995, and October, 1996. The American authors' position also varied from company representative to working level staff.

\section{Privacy and Confidentiality}

The identities of all the individuals and companies were completely confidential; therefore, personal backgrounds about authors (e.g., age, working experience, educational background) were unknown because the companies insisted on maintaining the privacy of their employees, company, and the companies they dealt with. To protect individual authors and companies, each letter is represented by a number in the context of the study.

\section{Data Analysis}

This study approached rhetorical differences between Korean and American business people in terms of organization and style. All the data were analyzed according to a predetermined set of coding categories both for organization and style patterns. 
1. Rhetorical organizational pattern

This study defined "organization" as the order in which ideas were presented at the discourse level; in other words, the organization depended on at what point, or in what order the writer's points were made. Primarily based on Connor, David, and Rycker's model (1995), a coding scheme for organization analysis was developed for this particular study.

\section{Table 3.}

Coding Scheme for Organization: Meaning Components of Business Letters of Complaint

Category Definition

I. Identification of problem a statement that identifies clearly what the problem is

II. Relevant information a statement that provides detailed explanations to support the problem that the writer presents

III. Request for action desired a statement that specifies a request for action that will solve or improve the problem

IV. Topic shift

a statement that introduces new information, and this information is not a problem or not related to support a problem

V. Buffer

a statement that provides a pleasant, or noncontroversial comment that neutralizes a complaint or negative message; this comment may occur anywhere within the text

As shown in Table 3, the researcher's coding scheme included basic "meaning components" of business letters of complaint (Connor et al., 
1995). The presence and sequential order of the above categories was crucial in deciding whether or not the organization directly developed the writer's point. At the quantitative level, the number of words in each category was counted to indicate the presence of that meaning component. The sequential order was analyzed by "move" patterns (Swales \& Najjar, 1987). The coding procedure is discussed in detail in Chapter IV when presenting and discussing the results of analysis.

The first three categories of meaning components (I, II, and III) were considered as major elements of "direct" development and the next category (IV) was an element of "indirect" organizational development. The last category (V), Buffer was regarded as an optional factor in this analysis. Buffer, by definition, is a pleasant, or "neutral, noncontroversial statement" to lead in to a negative message (Bovée \& Thill, 1995, p. 269), and including a buffer in a negative message is conventional in business writing (Ewald \& Stine, 1983, Murphy \& Hildebrandt, 1988, Bovée \& Thill, 1995, Harcourt, Krizan, \& Merrier, 1996). When using buffers, writers may begin with this preparatory statement to neutralize the complaint, or end with a favorable statement to reaffirm the business relationship. In organization, opening buffers can delay the direct introduction to the writer's point, and closing buffers can de-emphasize the negative messages or requests for action. In this manner, the presence or absence of a buffer can affect organizational patterns; thus, the buffer is considered to be 
closer to indirect development.

In addition to the presence and sequential order of meaning components, the organizational pattern analysis examined occurrences of "Lack of Specificity" in the meaning categories. In this study, "Lack of Specificity" occurred when statements did not contain sufficient details to be clearly understood. Because "Lack of Specificity" can be a characteristic that overlaps more than one meaning component, this factor was analyzed separately from other elements.

Finally, the analysis examined the use of connectives (e.g., first, second, however, therefore, besides, consequently) in the organization. Connectives are used "to bridge any gaps between sentences and paragraphs so that the thought can be carried forward smoothly" (Harris, 1982, p. 160). Thus, connectives are "explicit signals of discourse organization" in the argumentative letter (Virtanen, 1995, p. 541). The absence of explicit connectors might cut the flow of text and cause discontinuity of discourse, while their presence might give the impression of logical coherence. In business complaints, it is important for the writer to be logical and consistent, and appropriate use of connectives could help the reader to make connections between sentences, paragraphs or texts. For this reason, the use of connectives was taken into account for organization. To classify the use of connectives, Halliday and Hasen's coding scheme (1976) was adapted. 
2. Rhetorical style pattern

This study defined "style" as the writer's rhetorical strategy through linguistic choice and usage in delivery of complaint messages. In other words, these choices determine the writer's rhetorical style as either "implicit" or "explicit" when communicating a message. In order to analyze the style of letters written in the two different business communities, this study looked at four factors that might influence “explicitness" or "implicitness" of message: Lexical hedges, Impersonalization of complaint sources, "Intense" adjectives or adverbs, and Types of action requests. Table 4 divides the rhetorical styles into the four strategies.

After identification and classification, these four rhetorical strategies were analyzed according to their communicative functions: complaint acts and requests acts. The coding procedure of rhetorical strategies is discussed in detail in Chapter IV when presenting and discussing the results of analysis.

\section{(a) Complaint Acts}

In complaint acts, the first category analyzed was lexical hedges. Hedges are "words or phrases whose job is to make things more or less fuzzy" (Lakoff, 1973, p. 462). Brown and Levinson (1987) consider hedges as a politeness strategy to minimize losing "face" in communication, and these 
Table 4.

Rhetorical Strategies of Business Letters of Complaint

\begin{tabular}{ll}
\hline Category & Definition and Example \\
\hline Lexical hedges & $\begin{array}{l}\text { a rhetorical strategy that chooses indirect } \\
\text { expressions in order to soften bluntness. }\end{array}$ \\
& Example: possibly, maybe, perhaps, it could \\
be ..., some might be ..., etc.
\end{tabular}


viewpoints associate hedges with the indirect mode of expression. In general, complaints convey negative connotations, so in order to avoid strong impressions in a complaining act, writers might consider lexical hedges in written discourse. By using hedging words and phrases, writers can be indirect or inexplicit in voicing their opinion, and tone down the complaint in the letter. Considering the motivation for engaging hedges, they can be seen as a rhetorical strategy to maintain a polite tone. To classify the writer's hedging strategy, Salager-Meyer's functional categorization (1994) was adapted.

The second category analyzed was impersonalization of complaint sources (Hatch, 1992, p. 142). In composing business complaints, writers need to indicate that they are in a problematic situation because of something that readers did or did not do. Hatch (1992) presents "impersonalization of complaint sources" as a rhetorical strategy to avoid the absolute statement that "the behavior injured the complainer alone or the offender alone is responsible for the problem" (p. 142). In complaint letters, the writer is the complainer, and the reader is the offender. By impersonalizing or removing the complainer and/or the complainee, an uncomfortable situation is presented in a less offensive manner; thus, impersonalization tends to make complaint acts implicit. For example, "A possible conclusion is that an error has been made in calculations" as opposed to "I think your calculations are wrong." By using the passive 
voice, the first statement impersonalizes the entire situation. On the other hand, the personalization of the complaint source can be offensive and the complaint act can be explicit as in the second statement, which is more accusatory.

The third category analyzed was "intense" adjectives or adverbs. The use of these adjectives and adverbs is a common linguistic tool used to convey "emotional intensity" in communication (Frank, 1990, p. 17). In other words, by using "intense" (personal) adjectives or adverbs such as honestly, badly, absolutely, etc., writers can reveal or conceal their dissatisfaction, or threaten the reader.

(b) Request Acts

In request acts, as in complaint acts, the first category analyzed was lexical hedges. Requesting in the complaint letter indicates the writer's desire for the reader to bring about some desired action to solve or improve the problematic situation. By using hedging words, writers can avoid being "forceful" and possibly negative. In this manner, the use of lexical hedges can be seen as a "politeness strategy" (Brown \& Levinson, 1987). To classify the writer's hedging strategy, Salager-Meyer's functional categorization (1994) was adapted. 
The final category analyzed was types of action requests, which are practical elements in business complaint. In a request, the writer calls for action that will solve or improve the problem and different cultures approach this in different ways, with some action requests being implicit and some explicit. While an explicit statement of request is preferred in one culture, the same statement might not be preferred in another culture, and this cultural preference could affect the writer's linguistic choice. To classify the writer's request strategy, this study established eleven forms of action requests adapting Kim and Bresnahan's model (1994). The eleven forms were divided into two major strategies: direct action request and indirect action request (see Table 4).

\section{Characterization of Rhetorical Patterns}

Based on the results of data analysis, this study attempted to characterize rhetorical organization and style patterns of the two business letter groups. Table 5 depicts major characteristics of rhetorical patterns.

Organizational patterns are "direct" or "indirect." In "direct" patterns, the writer's points are developed sequentially without topic shifts. In "indirect" patterns, the writer's points are not in sequential order and topic shifts occur. Style patterns are "explicit" or "implicit." In "explicit" strategies, complaint acts are personalized and the writer's message is delivered through "intense" adjectives/adverbs. In "implicit" strategies, 
complaint acts are impersonalized and the writer's message is delivered through lexical hedges.

Table 5.

Characteristics of Rhetorical Patterns

\section{Organization:}

\section{Direct (Linear) development}

Writer's points are directly developed.

- Deductive

- Quasi-deductive

- I, II, and III are in sequential order

- IV and V may exist, but minimally

- "Lack of Specificity" may exist, but minimally
Indirect (Non-linear) development

Writer's points are indirectly developed.

- Inductive

- Quasi-inductive

- I, II, III are not in sequential order

- IV and $V$ exist

- "Lack of Specificity" exists

Style:

\section{Explicit strategy}

Writer's message is delivered in an explicit mode.

- Lexical hedges are seldom used

- Complaint acts are personalized

- "Intense" adjectives and adverbs reveal the writer's emotional state

- Action requested directly

\section{Implicit strategy}

Writer's message is delivered in an implicit mode.

- Lexical hedges are used

- Complaint acts are impersonalized

- "Intense" adjective and adverbs do not reveal the writer's emotional state

- Action requested indirectly 
CHAPTER IV

\section{ANALYSIS AND DISCUSSION}

\section{Length of Letters}

As Table 6 indicates, a comparison of the length of the letters revealed that the American letters were 106.86 words longer than the Korean letters; the average length of American letters was 264.86 words, while that of Korean letters was only 158 words. The letters within the Korean group showed a greater range between the shortest and the longest letter; in Korean letters the difference in length was 292 words, whereas the difference in American letters was 215 words. Especially in Korean letters, there was a strong tendency for short letters to contain more errors in grammar and more problems in paragraphing. In general, American letters were longer than Korean letters, and this difference in length might illustrate a difference in proficiency between L1 and L2 writers of English (Silva, 1993, p. 662).

Table 6.

Length of Letters

\begin{tabular}{lll}
\hline & $\begin{array}{l}\text { American } \\
\mathrm{n}=7\end{array}$ & $\begin{array}{l}\text { Korean } \\
\mathrm{n}=14\end{array}$ \\
\hline Total words & 1,854 & 2,212 \\
Mean & 264.86 & 158.00 \\
Median & 241 & 158.5 \\
Range & $182-397$ & $51-343$ \\
\hline
\end{tabular}




\section{The Format}

A comparison of the format of business fax letters showed similarities and differences. Usually both American and Korean business groups used the block style, and the indented style was used in only two American letters.

Most American and Korean letters had supplementary lines such as subject (SUB: ) or reference (RE: or REF:). Tables 7-1 and 7-2 illustrate that American letters had either $R E$ or $S U B$ and showed a preference for using $R E$, while Korean letters evenly used $R E$ or $S U B$, or both.

Table 7-1.

Supplementary Lines: American Letters

\begin{tabular}{ll}
\hline Letter ID & Description \\
\hline 1. & RE: Damaged shipment XX-268 \\
2. & RE: Air conditioners shortage \\
3. & REF: XXXX Electronics \\
4. & REF: XX/XXXXXXX and XXX \\
5. & - \\
6. & SUB: Trade Complaint - XXXXX Co. \\
7. & Concerning Non Payment of Funds for Equipment
\end{tabular}


Table 7-2.

Supplementary Lines: Korean Letters

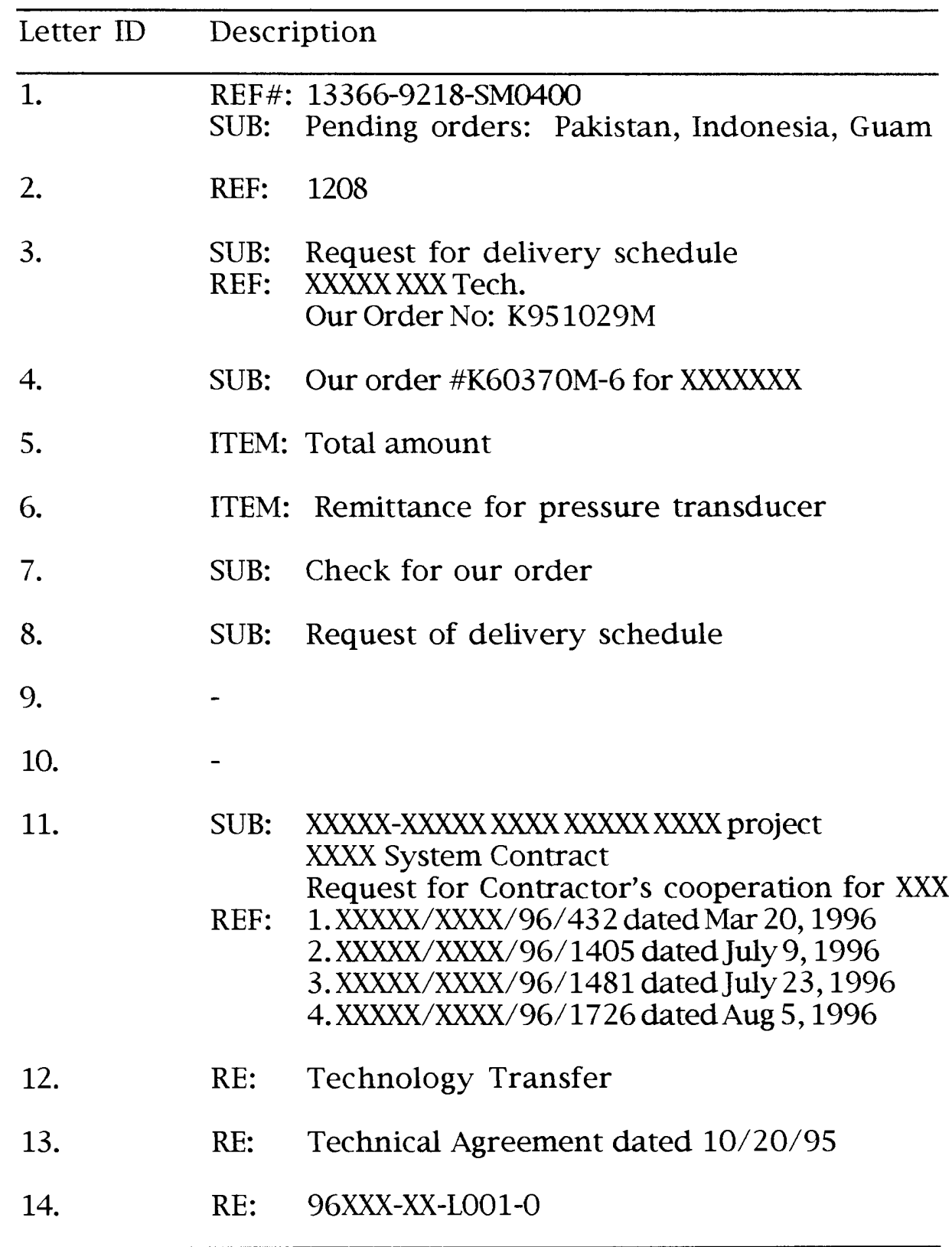

The supplementary lines in American letters provided more detailed and specific information in relation to the topic of letters. For example, 
in the case of Letter 2, the supplementary line played a role of "topic" statement; the text immediately provided explanatory information from the first line and never identified the "topic" again.

On the contrary, supplementary lines in Korean letters generally provided contextual information (e.g., REF: 1208 or SUB: Our order \#K60370M-6 for XXXXXXX) in relation to the business transaction; the supplementary line did not specify the "topic," but suggested the context to which the "topic" referred. For example, "request of [for] delivery schedule" in Letter 3 and 8 (see Table 7-2) meant "delay or late response of the delivery schedule" in the text; in the header, the complaint was not highlighted in the same way.

Overall, supplementary lines in American letters were more independent from the context and gave a clearer indication of the problem or complaint. Interestingly, letters in both business groups with no supplementary line at all appeared to use direct rhetorical patterns in organization.

In regard to the fax letter forms, both business groups used "in-house" developed designs that had the company's logo, name, and address printed. While Americans used their standard letterhead, Koreans used forms developed specifically for fax correspondence. For example, most layouts of Korean letter-heads included a separate header for basic elements such as DATE, FAX NO, FAX TO, ATTN, FROM, SUBJECT, Prepared by, 
Approved by, etc. A typical example is as follows:

\begin{tabular}{ll}
\hline Ref \#: & Date: \\
FAXTO: & Prepared by: \\
ATTN: & Approved by: \\
FROM: & \\
SUBJECT: & \\
\hline
\end{tabular}

The Approved by section showed that in major Korean companies, decisions are often made through supervisors, not solely by the working level staff.

Finally, salutations or complimentary closings were consistent in both American and Korean letters. Both communities tended to follow a formal tradition of business letters: Dear Mr. XXXXX, Sincerely yours, Sincerely, Best Regards, or Regards were commonly used.

\section{Rhetorical Organizational Patterns}

\section{Coding of Meaning Components}

The presence and sequential order of "meaning components" (I: Identification of problem, II: Relevant information, III: Request for action desired, IV: Topic shift, and V: Buffer) were significant factors in the analysis of rhetorical organizational patterns and their presence was operationalized in terms of the number of words and frequency of 
categories; the sequential order was operationalized in terms of the number of "moves."

This analysis identified the presence of meaning components and classified the statements in business letters of complaint according to the five-category coding scheme for organization (see Table 3). In many cases, the coding of the meaning components was consistent with the writer's strategies in paragraphing; however, in some cases, it was necessary to code on a sentence level. In other words, because of individual variance in paragraphing skill and strategy, in some letters all the components were contained within a single paragraph; therefore, it was sometimes necessary to approach the text sentence by sentence. After coding the entire text, the length of each category was calculated by the number of words in order to establish the presence of meaning components at a quantitative level. To code the sequential order of meaning components, a group of statements belonging to the same category was labeled as a "move" (Swales \& Najjar, 1987). In this study, when the writer shifted from one category to another category, that new category was considered another move. One move could contain several examples in the same category, but it never contained examples from different categories. Also, the move into the first entry was considered the first move.

In many letters, a whole paragraph consisted solely of the same meaning component; therefore, it was coded as one move. When the next 
paragraph or statement contained the same meaning component, it was grouped as the same move. Occasionally, a single paragraph or a statement included two or more different meaning components; when this occurred, each category shift was sequentially grouped as an independent move. The following section of text from the Korean corpus illustrates examples of the coding elements of moves in this study. To preserve format "originality," the original writer's errors and problems with grammar were untouched. The body of the original text is in brackets and the researcher's category numbers differentiating coding elements are parenthesized:

[ That is resulting in payment twice to one items,] (I) [ so we have solution under consideration.

1) we want to return money 935.00 US\$.

2) another, we want to purchase your products as much as that price.] (III)

[ We hope to select one condition, and send response to us as soon as possible.] (III) [ also want to receive answer our fax message on May. 3. 1996 (about delivery of pressure transducer)] (IV)

The first paragraph contains two meaning components: the first component identifies what the problem is (Category I: Identification of problem), and the second component states action requests by giving options (Category III: Request for action desired). Category I shifts to category III at the first comma in the first sentence, creating the move from I to III. The second paragraph also contains two meaning components: 
the first one is a restatement of action requests (Category III), and the second one is introducing new information which is totally unrelated to the business complaint (Category IV: Topic shift). Thus, category III in paragraph one continues on into paragraph two including the first sentence. The second sentence of paragraph two is the shift from Category III to Category IV; thus the third move. Although the text consisted of four meaning components (I, III, III, and IV), it is counted as three moves (I, III, and IV) because the second and the third components belong to the same Category III; therefore, this example text shows three moves. Figure 2 illustrates the three moves in sequential order:

"Move"

Meaning components

Category No. of moves

Category shift in sequential order
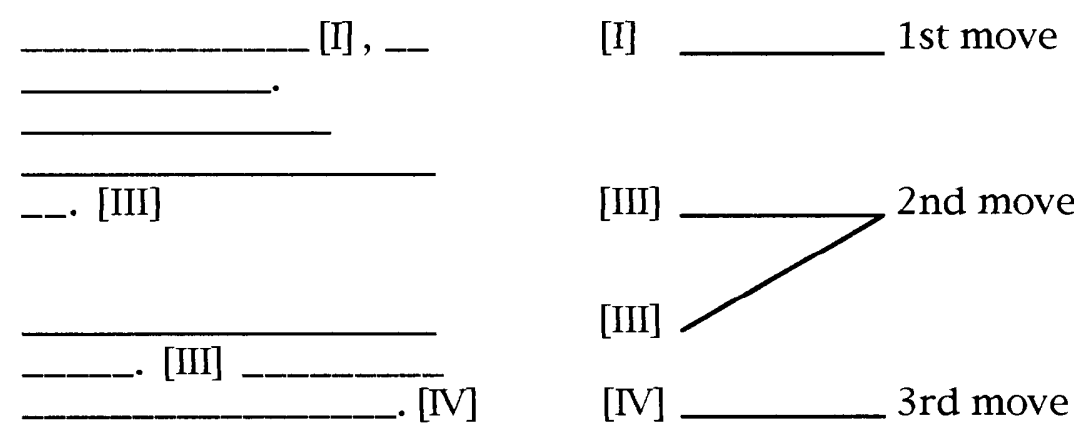

[IV] 3rd move

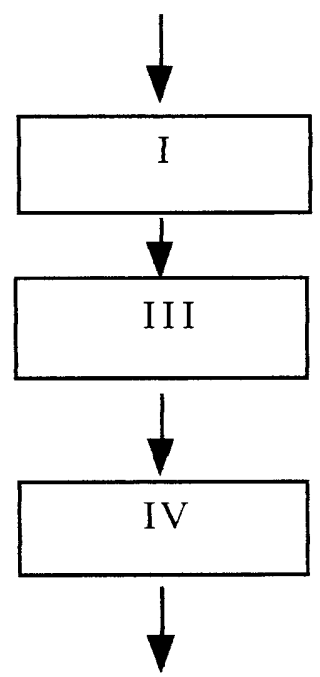

Figure 2. Illustrating "Moves" 
In the case of topic shifts (IV), when the topic changed more than once, each change to a new topic was counted as one move.

After the initial coding of meaning components, the letters were re-evaluated for "Lack of Specificity." This component was analyzed separately from other categories because it always occurred in conjunction with one of the other categories, and never occurred as an independent move. Thus, "Lack of Specificity" was not included in the sequential order analysis and its presence was coded independently in order to find out the occurrence within the meaning categories.

Finally, the coding of meaning components focused on the main body of the letter. In some letters supplementary parts such as subjects or reference lines were crucial in identifying meaning components. For example, if $R E$ (reference) in the message header exactly identified the problem, and the problem was never mentioned again in the text then it was necessary to include the supplementary line.

\section{The Presence of Meaning Components}

Most letters in both American and Korean business groups fit into the organizational structure of the meaning components of complaint letters. The study also found two other categories employed in real-life business communications; they were "threat" and "P.S." and both appeared only in Korean letters. 
For this study, Categories I, II, and III were considered as major elements of direct development and Category IV was an element of indirect development in organization. Category $\mathrm{V}$ was considered an optional element, but was closer to indirect development. Because "Lack of Specificity," as discussed in the coding section, overlapped with the other categories, it was coded separately and is presented in Table 11.

Table 8 illustrates the mean number of words and ratio of words per category of meaning components:

Table 8.

The Presence of Meaning Components

\begin{tabular}{lrrrrr}
\hline & & \multicolumn{2}{l}{$\begin{array}{c}\text { American } \\
\mathrm{n}=7\end{array}$} & \multicolumn{3}{l}{$\begin{array}{l}\text { Korean } \\
\mathrm{n}=14\end{array}$} \\
\hline & mean & percent & mean & percent \\
\hline I. & Identification of problem & 56.0 & 21.1 & 26.1 & 16.5 \\
II. Relevant information & 134.0 & 50.6 & 68.4 & 43.3 \\
III. Request for action desired & 69.3 & 26.2 & 39.7 & 25.1 \\
IV. Topic shift & - & - & 1.9 & 1.2 \\
V. Buffer & 5.6 & 2.1 & 15.1 & 9.5 \\
& Other ("threat", P.S.) & - & - & 6.7 & 4.3 \\
& & & & & \\
\hline & Total: & 264.86 & 100 & 158.00 & 100 \\
\hline
\end{tabular}

The results revealed some basic differences regarding the presence or absence of meaning component categories. Categories I, II, and III were present in both American and Korean letters, and the percentage of 
categorical distribution of each meaning component was similar; both appeared in the order of II, III and I. However, Category IV and "other" were present only in Korean letters. Also, while American letters were longer in the Categories I, II, and III, Korean letters were longer in Categories IV, V, and "other." Since Categories I, II, and III are considered major elements of direct development and IV is an element of indirect development in organizational patterns, these results indicate that, in terms of word count per category, American letters tend to be more direct than Korean letters in organizational patterns as shown in Figure 3:

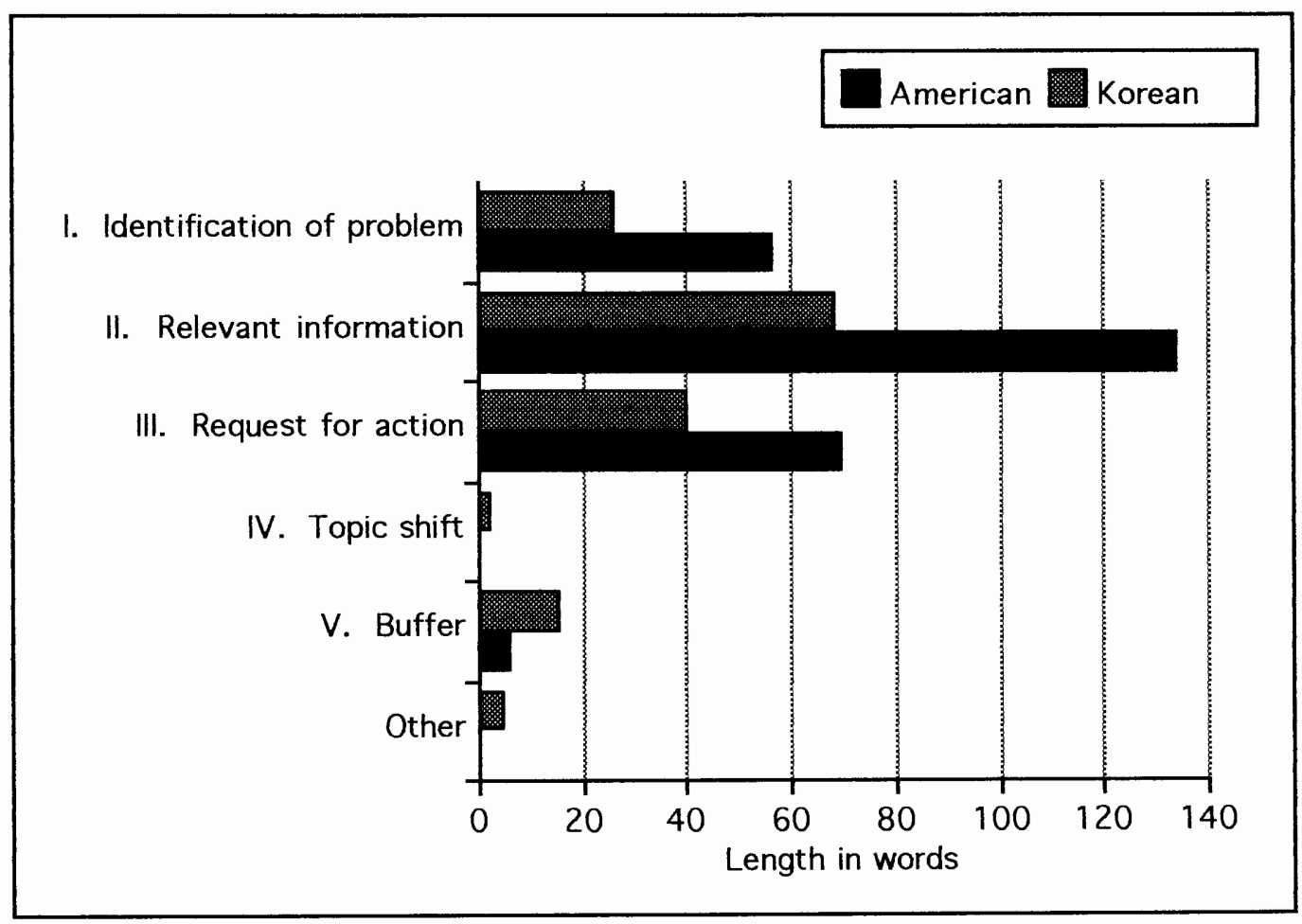

Figure 3. The Presence of Meaning Components 


\section{The Sequential Order of Meaning Components}

The sequential order of meaning components was categorized and analyzed in terms of "moves." For this study, a "move" was defined as a shift from one category of meaning components to another category of meaning components. The results of the sequential order analysis showed differences in the number of "moves" and "move" patterns between American and Korean letters.

In meaning categories, the number of moves in American letters was less than in Korean letters; the average number of moves in American letters was 4.14, while that of Korean letters was 5.57. As shown in Figures 4-1, 4-2a, and 4-2b, frequent category shifts in Korean letters created more moves and interrupted the sequential flow of categories I through III, while infrequent category shifts in American letters created consistency in the sequential moves of meaning categories. These results show that the arrangement of meaning components in American letters is more consistently organized than in Korean letters. 


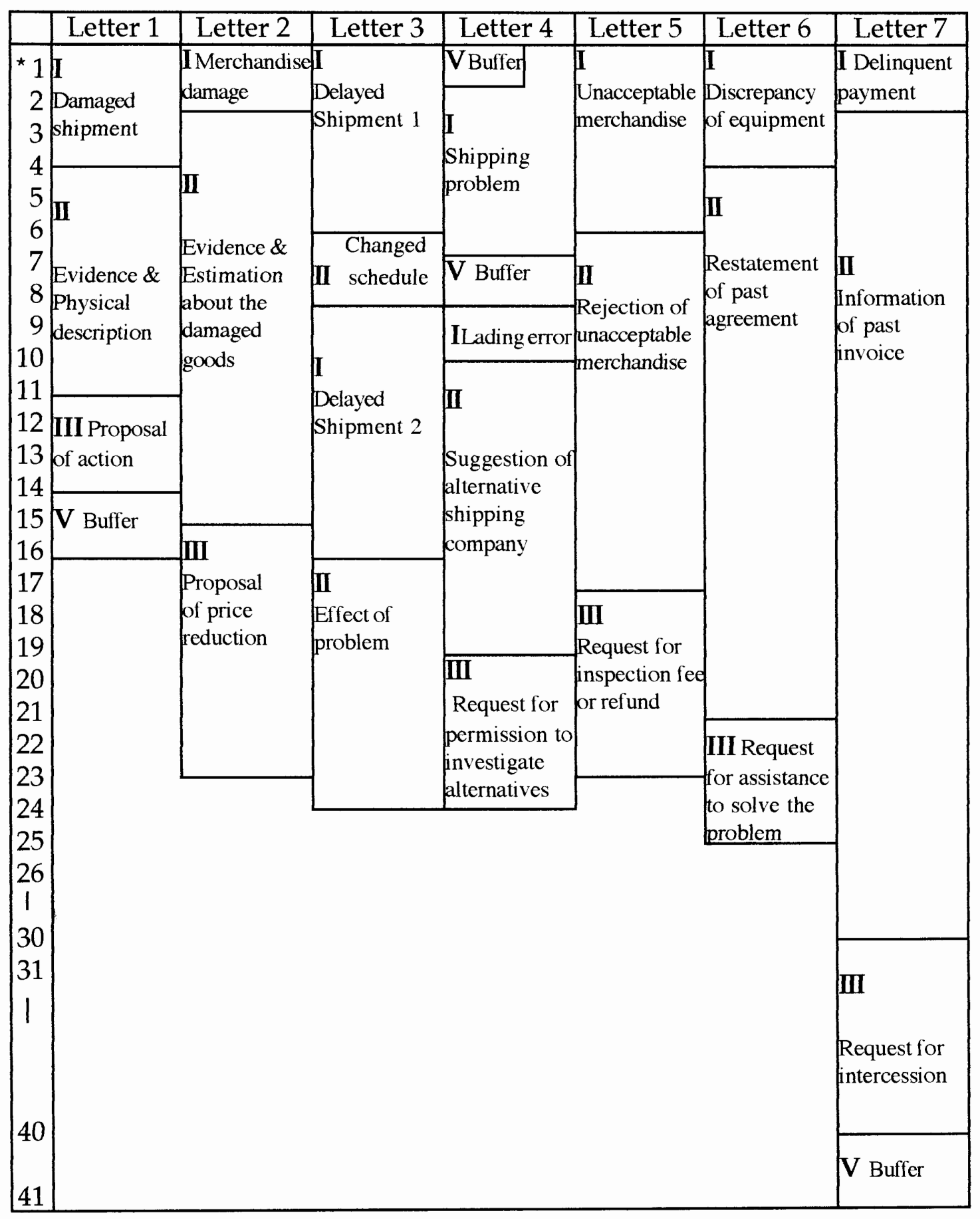

* Sequential order of lines in the letter

Figure 4-1. Sequential Order of "Moves": American Letters 


\begin{tabular}{|c|c|c|c|c|c|c|c|}
\hline & Letter 1 & Letter 2 & Letter 3 & Letter 4 & Letter 5 & Letter 6 & Letter 7 \\
\hline${ }^{\star} 1$ & \begin{tabular}{l|l} 
II & I \\
\end{tabular} & I & III & III & II Product & III & I No response \\
\hline 2 & & Shipment & Need of & Arrival of & I Wrong & Background & to question \\
\hline 3 & 3 III Intro. & schedule & merchandise & product & invoice & info. about & II Repeat \\
\hline 4 & statements & change & I Delayed & & & duplicated & questions \\
\hline 5 & & & delivery & I Problem & III Effect of & jinve & "Threat" \\
\hline 6 & $5 \mathrm{I}$ & & III Fax info. & III Fax info. & problem & & III Reply \\
\hline 7 & 7 Problem 1 & & & & & & "Threat" \\
\hline 8 & & III Importance & & & III Urge for & & V Buffer \\
\hline 9 & III Solution & "original" & & & explanation & & \\
\hline 10 & for problem 1 & schedule & & & V Buffer & fPayment & \\
\hline 11 & I Problem 2 & & & & "P.S." & & \\
\hline 12 & IIInformation & & & & & & \\
\hline 13 & I Problem 2 & $\begin{array}{l}\text { Request for } \\
\text { confirmed }\end{array}$ & & & & Proposal of & \\
\hline 14 & II Effect of & shipment & & & & & \\
\hline 15 & Problem 2 & schedule & & & & IV1 & \\
\hline 16 & III & & & & & Topic shift & \\
\hline 17 & Action for 2 & & & & & & \\
\hline 18 & I Problem 3 & & & & & Tonic shift & \\
\hline 19 & & V Buffer & & & & & \\
\hline $\begin{array}{l}20 \\
21\end{array}$ & $\begin{array}{l}\text { Solution for } \\
\text { Problem } 3\end{array}$ & & & & & V Buffer & \\
\hline 22 & $\checkmark$ Buller & & & & & & \\
\hline 23 & & & & & & & \\
\hline 24 & & & & & & & \\
\hline 25 & & & & & & & \\
\hline $\begin{array}{l}26 \\
27\end{array}$ & & & & & & & \\
\hline $\begin{array}{l}27 \\
28\end{array}$ & & & & & & & \\
\hline 29 & & & & & & & \\
\hline 30 & & & & & & & \\
\hline $\begin{array}{l}31 \\
32\end{array}$ & & & & & & & \\
\hline
\end{tabular}

* Sequential order of lines in the letter

Figure 4-2a. Sequential Order of "Moves": Korean Letters 1-7 


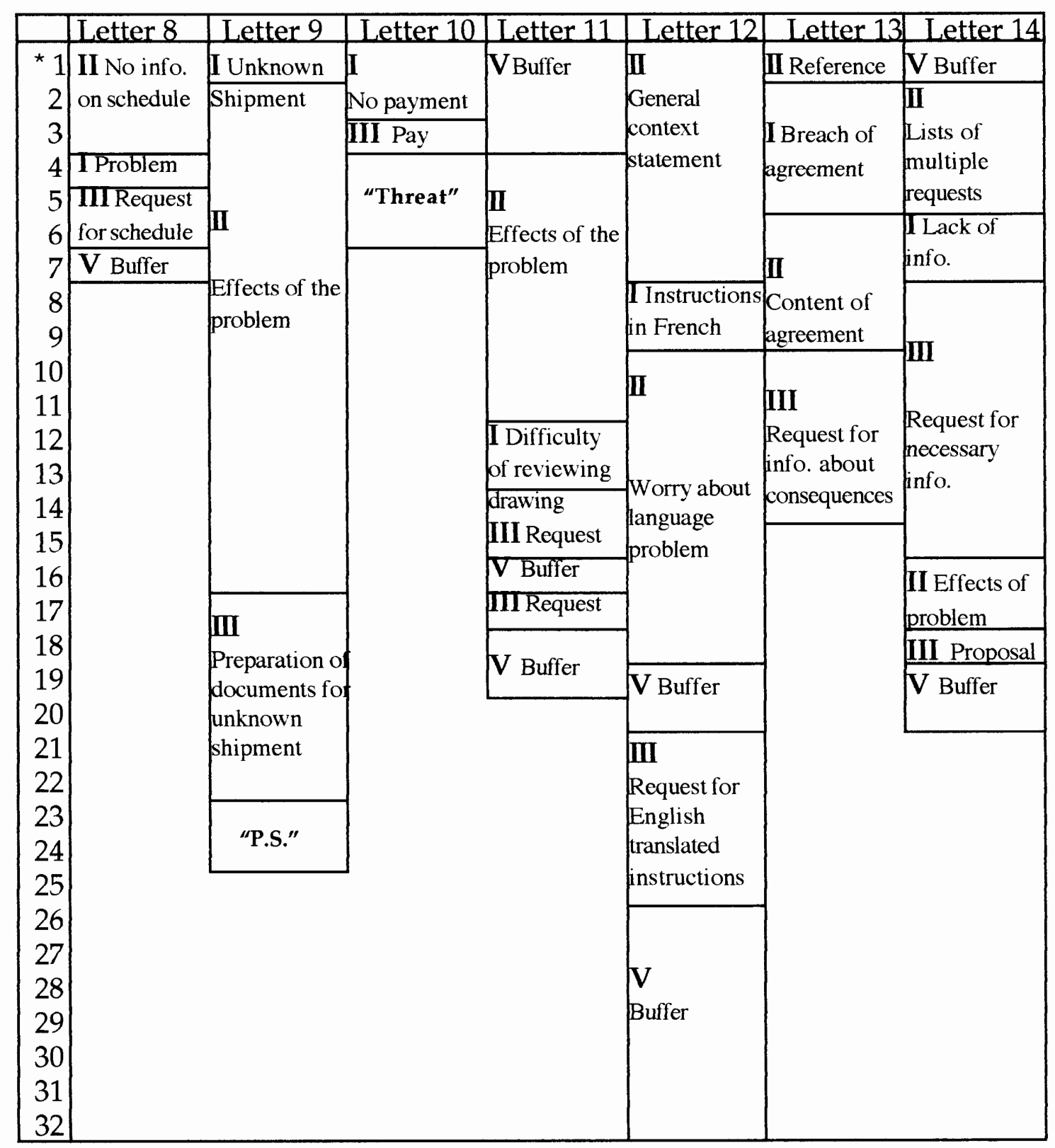

* Sequential order of lines in the letter

Figure 4-2b. Sequential Order of "Moves": Korean Letters 8-14 
The following are general "move" patterns for both American and Korean letters according to Figure 4-1 and 4-2a \& 4-2b:

"Moves"
in American Letters
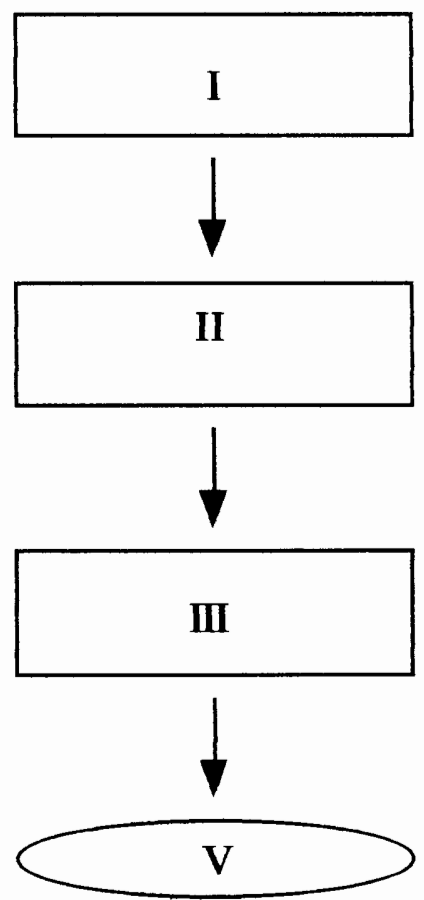

"Moves"

in Korean Letters

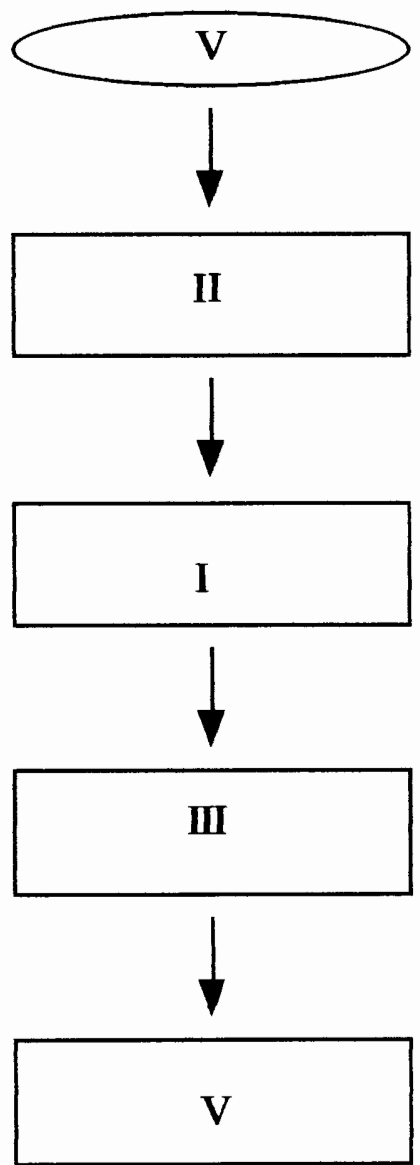

*Note: The circle designates an optional move.

Figure 5. Model of General “Move” Patterns 
The majority of move patterns in the American letters analyzed for this study exactly match the American model shown in Figure 5. Also, a close look at the content of meaning components in American Letter 1 leads to the following organizational structure:

\author{
I: Identification of problem \\ I.a. Clear definition of problem 1 \\ I.b. Clear definition of problem 2 \\ II: Relevant information \\ II.a. Evidence of problem \\ II.b. Physical description of problem \\ III: Request for action desired \\ V: $\quad$ Buffer \\ Possible solution to the problem \\ Appreciation and thank you
}

This pattern is clearly seen in the following text from American Letter 1:

[We have been informed by our customer XXXX Trading Corporation that upon receipt of shipment XX-268 the product was found to be damaged and unacceptable for sale.] (I.a) [In addition to damaged goods, it was found the order not to be complete with several pieces of merchandise missing totally from the container.] (I.b)

[Attached is copy of a memo our Customer Service department received from Mr. XXX XXXXX, marketing director at XXXX Trading Corporation. Mr. XXXXX has supplied us with documentation and photographs taken at arrival of the container.] (II.a)

[It was found this load has missing product, empty cartons, scrap wood enclosed within sealed packaging, dirty cartoning, and product with missing components. Attached is the original copy of the "Certificate of Expert's Examination" and a translation of this document.] (II.b)

[XXX Trading Corporation has proposed a credit of $\$ 9655.00$ be made to the invoiced total. Please review with your people and advise as to the alternatives XXXXXX suggests to satisfy this customers position with this shipment.] (III)

[Your involvement into order XX-268 is appreciated. Thank you and we are awaiting your quick response.] (V) 
In this example, the text starts with Category I, then shifts to Category II.a and II.b, and continues to Category III in sequential order; finally Category III shifts to optional move, Category V.

On the other hand, the move patterns in the majority of Korean letters do not exactly match the Korean model in Figure 5. However, because the sequence of meaning components in each Korean letter does follow this pattern with slight deviations, the Korean model is considered a standard general model. Thus, the standard model provides an outline to illustrate various patterns of moves in Korean letters. Also, a close look at the content of meaning components in Korean Letter 14 shows the following organizational outline:

V: $\quad$ Buffer (Opening)

II: Relevant information

II.a. Detailed background information

I: Identification of problem

Identify need for response previously requested

III: $\quad$ Request for action desired

III.a. Request a reply for necessary information

[Deviations] II.b. Consequence of unsolved problem III.b. Proposal a solution to the problem

V: $\quad$ Buffer (Closing)

Wishing cooperation and effort in the future

This Korean move pattern with slight deviation is shown in the following text: 
[First of all, we would like to thank you for your kind cooperation during last year.] (V:Opening)

[As you know well, JJJ activity needs a long time to make a final conclusion. Last year at the management level meeting, which were held 2 times, and through so many times JJJ international meeting, we had requested for JJJ activities so many times (JJJMJ-Q038, JJJ-MJ-Q045, JJJ-MJ-Q046, etc).] (II.a) [In spite of our requests, we don't have any clear answer from you about that. Now we are very anxious for schedule impact and additional expenses very seriously.] (I)

[Then we would like to remind you of our request one more time as follows:

-Full B.O.M.

-A,B,C,D classification in according to B.O.M.

-supplier list (minimum 2 suppliers) in according to

B.O.M.

-Homologation procedure

-Vendor qualification procedure

-Procurement spec, and its related document

-Detail procurement activity schedule] (III.a)

[Considering XXX's production schedule in XXX, present situation in JJJ could result in a XXX's human resource \& material loss, delivery schedule impact.] (II.b) [We think the only thing to solve these problems should be proposed and drawn from by you.] (III.b)

[In 1996, to solve all problems, we wish your good cooperation and best efforts would be awaited.] (V: Closing)

In this example text, meaning components are arranged in the order of $\mathrm{V}$,

II, I, III and V; II.b and III.b are deviations of the standard Korean model.

However, these deviations within the text are not significant enough to

change the standard move pattern in Korean letters because the

information provided within the deviations (II.b \& III.b) are subcategories

of the previous major categories II and III. The information in the

deviations actually belongs to the same meaning components that preceded 
them. For example, Category II.a and II.b might be grouped together, and III.a and III.b might also be grouped together.

In Korean letters only 4 out of 14 followed the American standard model; the majority of Korean letters were in variant forms of the Korean standard model such as II, I, III and closing V with an opening V occasionally added, and various deviations inserted in the middle of the text. This sequential arrangement of meaning components in Korean letters suggests that the writer provides preparatory or explanatory information before stating the main idea. In presenting a business complaint, the delay in identification of the problem and request for action shows an indirect approach; therefore, in Korean letters the indirect organizational pattern is dominant, and direct development is rare. Moreover, while similar information might be grouped together into one meaning category, it is placed randomly within the text. This separation creates unnecessary moves and makes the Korean letters appear discontinuous and digressive in organization.

On the other hand, 5 out of 7 American letters appeared to follow the American standard pattern of moves as seen in Figure 5; thus, the overall arrangement of meaning categories appeared I, II, and III in sequential order, with Category $\mathrm{V}$ added sometimes as a final move. This sequential arrangement of meaning components illustrates that in American letters the main idea (problem) is presented first, then explanatory details follow. 
In terms of presentation of business complaints, this is a direct approach and to the point. Similar information was presented together and not divided within multiple places in the letters. For example, all of the information that was in Category II was presented in one move creating a direct organized presentation of information. Thus, direct organizational patterns are dominant in American letters.

At rhetorical level organization, Topic Shift (IV) is a critical element to consider in indirect development because the appearance of Topic Shift interrupts the "moves" of meaning components. The results revealed two incidents of Topic Shift in only one Korean letter and none in American letters. Because of the narrow focus of business discourse, topics were narrowed down to relevant business transactions, so the opportunity for Topic Shift was limited. In this study, Topic Shift appears not to be a prominent factor in the development of organizational move patterns because it occurred only in one letter out of both groups; however, its existence suggests one factor contributing to the indirect development in Korean letters. Thus, it is significant to note that it did occur in a Korean letter but not at all in American letters.

\section{Buffers}

As an optional meaning component category in organizational patterns, Buffer (V) also appeared to contribute to the indirect development 
of Korean letters. This analysis divided buffers into three major categories: Opening, Middle, and Closing depending on where they were located within the letter. Opening buffers occurred at the beginning or in the first paragraph, and were divided into two types: greeting and intentional. An intentional buffer went beyond conventional greeting buffers in that it was related to concern of the letter or the message, and it did not function as greeting. An opening greeting buffer (OGB) was a pleasant, simple greeting such as "Good day Mr. XXX" (American Letter 4); an opening intentional buffer (OIB) was beyond a simple greeting, "First of all, we would like to thank you for your kind cooperation during last year" (Korean Letter 14). Middle buffers (MB) occurred in the middle of the text; because of the location they were not greetings, and thus all were considered intentional buffers, "As you know we have always given XXXXX our immediate attention, ..." (American Letter 4). Closing buffers occurred at or near the end of the text, and were divided into two types: complimentary and intentional. A closing complimentary buffer (CCB) was an extended complimentary closing in addition to a standard closing such as "Regards or Sincerely." An example of a closing complementary buffer was "Thank you for your help in this matter" (American Letter 7). A closing intentional buffer (CIB) was longer and more descriptive than a complimentary closing buffer, "Anyway we hope to continuously make good relationship with your company" (Korean Letter 6). 
Table 9.

Occurrences of Buffers

\begin{tabular}{lcc}
\hline Characteristics of buffer & $\begin{array}{c}\text { American } \\
(\mathrm{n}=7) \\
\text { Number of words }\end{array}$ & $\begin{array}{c}\text { Korean } \\
(\mathrm{n}=14) \\
\text { Number of words }\end{array}$ \\
\hline 1) Opening & 4 & - \\
$\quad$ a) Greeting & - & 52 \\
b) Intentional & 11 & 30 \\
2) Middle & 8 & 6 \\
3) Closing buffer & 16 & 123 \\
$\quad$ a) Complimentary & & 211 \\
b) Intentional & 39 & 15.07 \\
\hline Total number of words: & 5.57 & \\
Mean number of words: & 5.5 & \\
\hline
\end{tabular}

Table 10-1.

Types and Usage of Buffers: American Letters

\begin{tabular}{lc|cc|l}
\hline Letter ID & OGB & $\begin{array}{r}\text { OIB } \\
\text { Intentional }\end{array}$ & $\begin{array}{c}\text { CIB } \\
\text { Buffers }\end{array}$ & CCB \\
\hline 1. & & \multicolumn{3}{c}{} \\
2. & & $*$ & \\
3. & & & & \\
4. & $*$ & $*$ & & \\
5. & & & & \\
6. & & & & \\
7. & & & $*$ \\
\hline
\end{tabular}


Table 10-2.

Types and Usage of Buffers: Korean Letters

\begin{tabular}{lc|cc|c}
\hline Letter ID & OGB & $\begin{array}{r}\text { OIB } \\
\text { Intentional }\end{array}$ & $\begin{array}{c}\text { CIB } \\
\text { Buffers }\end{array}$ & CCB \\
\hline 1. & & & & $*$ \\
2. & & & & $*$ \\
3. & & & & \\
4. & & & $*$ & \\
5. & & & $*$ & \\
6. & & & $*$ & \\
7. & & & $*$ & \\
8. & & & & \\
9. & & $*$ & $*$ & \\
10. & & & $*$ & \\
11. & & $*$ & & \\
12. & & & & \\
13. & & & & \\
14. & & & & \\
\hline
\end{tabular}

As shown in Tables 9, 10-1, and 10-2, Buffers (V) were present in both American and Korean business letters although the analysis revealed important differences between the two groups. First, the use of buffers in the American letters was almost minimal (2.1\%) compared with meaning component categories I through III, whereas buffers were considerable (9.5\%) in Korean letters (see Table 8). In terms of frequency, 14 total buffers were found in 10 out of 14 Korean letters, and 4 buffers appeared in 3 out of 7 American letters. This indicates that buffers are more prevalent in Korean business letters than in American. 
Second, the characteristics of buffers in Korean letters were distinctive, while they were not in American letters. In Korean letters the majority of buffers were found in intentional buffer categories as shown in Table 10-2. This result shows that the Korean buffers were primarily devoted to the purpose of softening the negative message of complaint. On the other hand, the 4 buffers used in American letters were all in different categories, and only two of them were intentional; therefore, the same conclusion cannot be drawn. For example, consider the following text from Korean Letter 7:

[we don't want to develop legal problem in this situation.] (Threat) [if you did not connect out fax (82-XXX XX XXXX), we introduce another fax number ( $82 \mathrm{XXX}$ XX XXXX) to you.] (CIB)

On the surface, the last two lines seem to provide a piece of information about a fax number; however, this information was given right after a "threat" or strong warning for the problematic situation. Within this context, the last two lines soften the impact of the message and give the reader a way out of the situation. Thus, the last two lines function as a buffer by neutralizing the "threat" in the previous line.

Although buffers appeared in both communities, of 4 buffers in American letters, only two were intentional; in the Korean letters 11 of the 14 buffers were intentional. The frequency and usage of opening and middle intentional buffers seems to be the indication of indirect 
development because they delay the immediate introduction of the problem and interrupt the sequential flow of meaning components I through III. Also, even though closing intentional buffers do not interrupt the flow of meaning components, they might be considered indirect as well because they provide superfluous information that was unnecessary to the business complaint.

Others ("Threat" and "P.S.")

This analysis also found two other elements used in real-life business complaints. They were "threat" and "P.S." Interestingly, both categories were found only in Korean letters. Among two examples of "threat," the first example was partially presented on the previous page (p. 71) in the discussion of buffers (Korean Letter 7). The following text shows the entire threat:

[it is face with our limitation of endurance to wait.] (Threat:1a) [we are again await your sincerely answer, we expect to receive immediately answer.] (III)

[we don't want to develop legal problem in this situation.] (Threat:1b) [if you did not connect out fax (82-XXX XX XXXX), we introduce another fax number (82-XXX XX XXXX) to you.] (V)

This example shows the threats (1a and $1 \mathrm{~b})$ come in the "move" between Category III and Category V. Since Threats $1 \mathrm{a}$ and $1 \mathrm{~b}$ do not appear consecutively, the sequential flow is interrupted. The other example of a 
"threat" was from Korean Letter 10:

Please settle the open invoice.

[If you don't settle it by Feb. 28, your Embassy in XXXXX

will take a step against you.

This fax will be faxed to the Embassy tomorrow.] (Threat 2)

Unlike the previous example of "threat", in which parts of the threat are divided, in this example all elements of the "threat" are together, so it doesn't interrupt the "move" between meaning component categories.

Also, it was unusual to find "P.S." in business letters. "P.S." appeared twice in only Korean letters and in both cases, "P.S." was relevant information that should have been included earlier in the letter with the rest of Category II; thus, it interrupts the sequential flow of categories. Overall, "threat" and "P.S." contributed to digressive organizational patterns.

\section{"Lack of Specificity"}

In addition to the presence and sequential order of meaning components, this study was interested in occurrences of "Lack of Specificity" in the meaning categories. In this study, "Lack of Specificity" occurred when the statement did not contain sufficient details to be clearly understood. Because "Lack of Specificity" can be a characteristic in the content of meaning components, this factor was coded separately from 
other categories, and the analysis revealed significant differences, in terms of frequencies, between American and Korean letters:

\section{Table 11.}

\section{Occurrences of "Lack of Specificity"}

\begin{tabular}{lll}
\hline Letter ID I II III IV V \\
\hline American Letters & & \\
1. & & \\
2. & & \\
3. & & \\
4. & & \\
5. & $*$ & \\
6. & & \\
7. & & \\
& & \\
\end{tabular}

\section{Korean Letters}

1.

2.

3.

4.

5.

6.

7.

8.

9.

10.

11.

12.

13.

14.

$*$
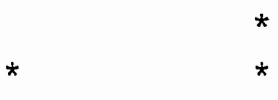

6.

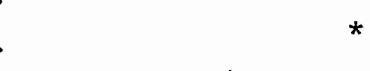

*

.

11.

13.

14.

In Table 11, it is evident that "Lack of Specificity" (LOS) was frequent in Korean letters, whereas it was infrequent in American letters: occurring 9 times in seven Korean letters and twice in only one American letter. Since 
"Lack of Specificity" occurred only twice in American letters, it was not significant to suggest patterns of appearance; however, in Korean letters this component often occurred in conjunction with Category I and III. For example, consider the following text from Korean Letter 8:

We have sent facsimile message to you about delivery schedule and shipping information. but, we did not receive your any answer except your fax (Dec 18. 1995: you will ship this week)

[Now, we have many problem due to your products.] (I)( ${ }^{\mu L O S ")}$ anyway we hope to receive some information to you. (shipping schedule, flight No., B/L copy ..... etc)

The text in brackets is Category I meaning components, and it was labeled "Lack of Specificity" due to lack of detailed information about "many problem." In general, this text is short, and the problem is stated only in the words "many problem"; thus, explanation about the problems themselves is missing.

In another example (Korean Letter 12), "Lack of Specificity" was seen in Category II. For example,

[We received a series of reports recently from both XXXXX and XXXXX plant containing our trainees' concerns over the ongoing trainings mainly for Methods and Toolings for Structures.] (II) (“LOS")

Because this text was placed in the first paragraph, the text played the role of an introductory statement regarding the problem, and delayed the introduction of main ideas. Similarly, this paragraph is ambiguous; it is unclear how many reports were received, what the concerns of the trainees 
were, and finally, it is confusing whether "Methods and Toolings for Structures" was part of the concern or the topic of the training. Thus, this introductory paragraph omits the relevant statement of the exact problem. In this case, "Lack of Specificity" seems to be the prevailing characteristic of this opening paragraph.

Finally, "Lack of Specificity" occurred in Category III as a request for action. For example, in Korean Letter 4 Category III was stated in only one sentence: "Please advise us by fax." This statement is not specific and it is unclear what "advice" or information is being requested. In Korean Letter 14 , the action request is:

[We think the only thing to solve these problems should be proposed and drawn from by you.] (III)

In this example, the action request is also not specific regarding exactly what the writer wants the reader to do in order to solve the problems. In addition, the active to passive sentence structure and the misuse of "from" instead of "up" makes the sentence meaning ambiguous.

"Lack of Specificity" occurred in only one American Letter (6) which seems to have been sent from the complaining company to a mediator. In this letter, "Lack of Specificity" appeared in both categories I and III. For example,

[I am in receipt of your FAX dated August 23, 1996. It appears that a discrepancy exists.] (I)(“LOS") 
In this example, the first sentence is an opening in which the writer implies that he/she wants the reader to refer to the mentioned fax. Unfortunately, this letter was written in Oct 15, 1996, so two months have elapsed since the company sent the fax. This leads to an ambiguous situation for the reader; to even begin to understand the problem, the reader has to find the fax mentioned or remember what was in the original fax. Similarly, in the next sentence the writer doesn't say for certain if there is a definite discrepancy or what the discrepancy is. The writer assumes that the reader knows the problem, and it is not necessary to redefine it. Overall, rather than including details, this writer puts the responsibility for finding the problem, and determining the discrepancy onto the reader.

In the same letter, another "Lack of Specificity" was also found in Category III. Usually American letters give precise instructions when requesting action as seen in American Letter 5 below:

[XXX Manufacturing Company needs this matter resolved by year end. Please resolve this matter honorably by sending us $\$ 500$ to conduct an inspection acceptable to you or refund us the amount already paid for these unusable and unacceptable castings.] (III)

However, in Letter 6 , the following statement occurs:

[It is our objectives to resolve this problem as soon as possible and any assistance you may give us will be appreciated.] (III)

This example lacks details in two respects. First, the writer does not specify when he/she wants the problem resolved. Second, he/she does not specify 
what assistance is preferred. The writer does not explicitly say "please rectify a specific problem" but instead, makes a general, ambiguous plea for assistance in an unspecified amount of time. Through these missing details, the writer gives the mediating party the choice of methods of assistance and time frame, whatever the mediator might need to deal with the complaint.

The discussions of the above examples illustrate that "Lack of Specificity" in the Korean letters is related to a lack of essential details and ambiguous sentence structure. However, in the American Letter 6 "Lack of Specificity" seems to serve a purpose; the writer could be softening the problem for the reader while purposely being ambiguous when asking for help in order to allow the reader choices. Therefore, in American letters "Lack of Specificity" seems to be "conscious," whereas in Korean letters "Lack of Specificity" occurs because of insufficient details and within grammatical anomalies.

Finally, it is interesting to note that "Lack of Specificity" never occurred in Category V and "Others" (P.S. and Threat).

\section{Connectives}

In terms of rhetorical pattern analysis, this study was also interested in the use of connectives because connectives are a linguistic device that helps smooth transitions in discourse organization. In this study, connectives are "conjunctions, adverbials and prepositional phrases, which 
indicate relationships between propositions in text" (Mauranen, 1993, p. 9). Table 12 summarizes and compares the use of connectives in both American and Korean letters according to their semantic functions; classification is a variation of Halliday and Hasan's coding system (1976, p. 226). In Table 12, the most often used connectives ( 3 times or more) in both American and Korean groups of letters are marked by an asterisk:

Table 12.

Use of Connectives

\begin{tabular}{|c|c|c|}
\hline & American & Korean \\
\hline$\overline{\text { Additive }}$ & $\begin{array}{l}\text { *also } \\
\text { furthermore } \\
\text { in addition to }\end{array}$ & $\begin{array}{l}\text { *also } \\
\text { furthermore } \\
\text { besides, and }\end{array}$ \\
\hline Optive & or & or, another \\
\hline Adversative & but, however & ${ }^{*}$ but, however \\
\hline Causal & so, because & $\begin{array}{l}\text { *so, because } \\
\text { therefore }\end{array}$ \\
\hline Temporal & & $\begin{array}{l}\text { first of all } \\
\text { lastly }\end{array}$ \\
\hline Exemplifier & & $\begin{array}{l}\text { for example } \\
\text { to name a few }\end{array}$ \\
\hline Subject changer & & *anyway \\
\hline Tense changer & & ${ }^{*}$ now \\
\hline Prepositional & & $\begin{array}{l}\text { in the mean time } \\
\text { for that matter } \\
\text { in the circumstance }\end{array}$ \\
\hline
\end{tabular}

${ }^{*}$ means that connectives are used three times or more. 
As Table 12 shows, in terms of frequency and variety, the use of connectives in American letters was less than in Korean letters. However, in terms of the appropriate use of connectives, the data analysis showed that some connectives in Korean letters were overused and misused, while none were used inappropriately in American letters. For an example of misuse, consider the following text from Korean Letter 6:

... we have solution under consideration.

1) we want to return money 935.00 US\$.

2) another, we want to purchase your products as much as that price.

In this example, another is used as an Optive for the purpose of presenting options in the context of the letter. However, grammatically another is not an optive connective; instead, or should be used.

In addition, the analysis showed two Korean "favorite" connectives. Among the five most frequently used connectives (marked by the asterisks in Table 12), anyway and now appeared only in Korean letters, while the three connectives, also, but, and so appeared in both American and Korean letters. However, the occurrences of anyway and now were unnecessary and their appearances misleadingly undermined the importance of the "problem" discussed within the letter. For example, consider the following text from Korean Letter 8: 
[We have sent facsimile message to you about delivery schedule and shipping information.

but, we did not receive your any answer except your fax (Dec 18. 1995: you will ship this week)] (II)

Now, [we have many problem due to your products.] (I) anyway [we hope to receive some information to you. (shipping schedule, flight No., B/L copy ..... etc)] (III)

In this example text, three connectives are used: but, now, and anyway. The first Adversative connective, but functions to express the contrast between the first sentence and the second sentence, and it is placed at the initial position of the second sentence. Although this connective is a correct choice, its placement is grammatically awkward; instead, it should have been combined with the first sentence using a comma. The second connective, now is used as a transitional device to shift discourse tense during the "move" between Categories II and I; this tense shift creates a cause-effect relationship using time. Rather than creating this relationship by using "because," the writer creates a shift from the past to the present tense. That confuses cause and effect in business discourse. The third connective, anyway (Subject changer) is used as a transitional device to shift from Category I to III. Its use is unnecessary and inappropriate because it is not the topic that has changed, but the "move" category within the same topic; thus, its appearance distracts from the consistent flow of logic, and impairs the reader's recognition of the problem.

In this example, the connectives are generally overused and misused 
because the writer heavily depends on them in discourse organization. The above discussion regarding the connectives now and anyway illustrates that the writer used the connectives when moving between categories II to I and I to III. The writer tried to make a transition, but the inappropriate use of connectives makes the "moves" confusing and the texts incoherent.

Even though American letters used fewer connectives, the analysis still showed that overall American texts were more consistently organized and directly developed. By contrast, Korean letters contained a larger number and greater variety of connectives, but the analysis revealed that several misused connectives diverted the direction of "important" business discourse, leading to incoherent organization. In terms of rhetorical organization pattern analysis, this result indicates that inappropriate use of connectives is one factor contributing to digressive development in Korean business letters.

\section{Rhetorical Style Patterns}

\section{Coding of Rhetorical Strategies}

Four rhetorical strategies and their use were determining factors in the analysis of rhetorical style patterns. The four rhetorical strategies were: Lexical hedges, Impersonalization of complaint sources, "Intense" (or Personal) adjective/adverbs, and Types of action requests (see Table 4). For the use of hedges and "intense" adjective/adverbs, all occurrences of these 
rhetorical strategies were counted in terms of the number of sentences that contained these linguistic elements. In the use of impersonalization of complaint sources, the strategy types were categorized as either impersonal or personal; in the use of action requests, the strategy types were categorized as either direct or indirect.

After identification and classification, these four rhetorical strategies were divided into two major categories, complaint act and request act according to their communicative functions. The rhetorical strategies included in the complaint act were: Lexical hedges, Impersonalization of complaint sources, and "Intense" (personal) adjectives or adverbs; the rhetorical strategies in the request act were Lexical hedges and Types of action requests. Because lexical hedges were used in both complaint and request acts, hedges in meaning component Categories I and II were considered complaint acts; hedges in meaning component Category III were considered request acts.

Figures $6-1,6-2 a$, and $6-2 b$ summarize the use of the rhetorical strategies in business letters of complaint from both American and Korean business groups. For explanation and example of each rhetorical strategy see Table 4. 


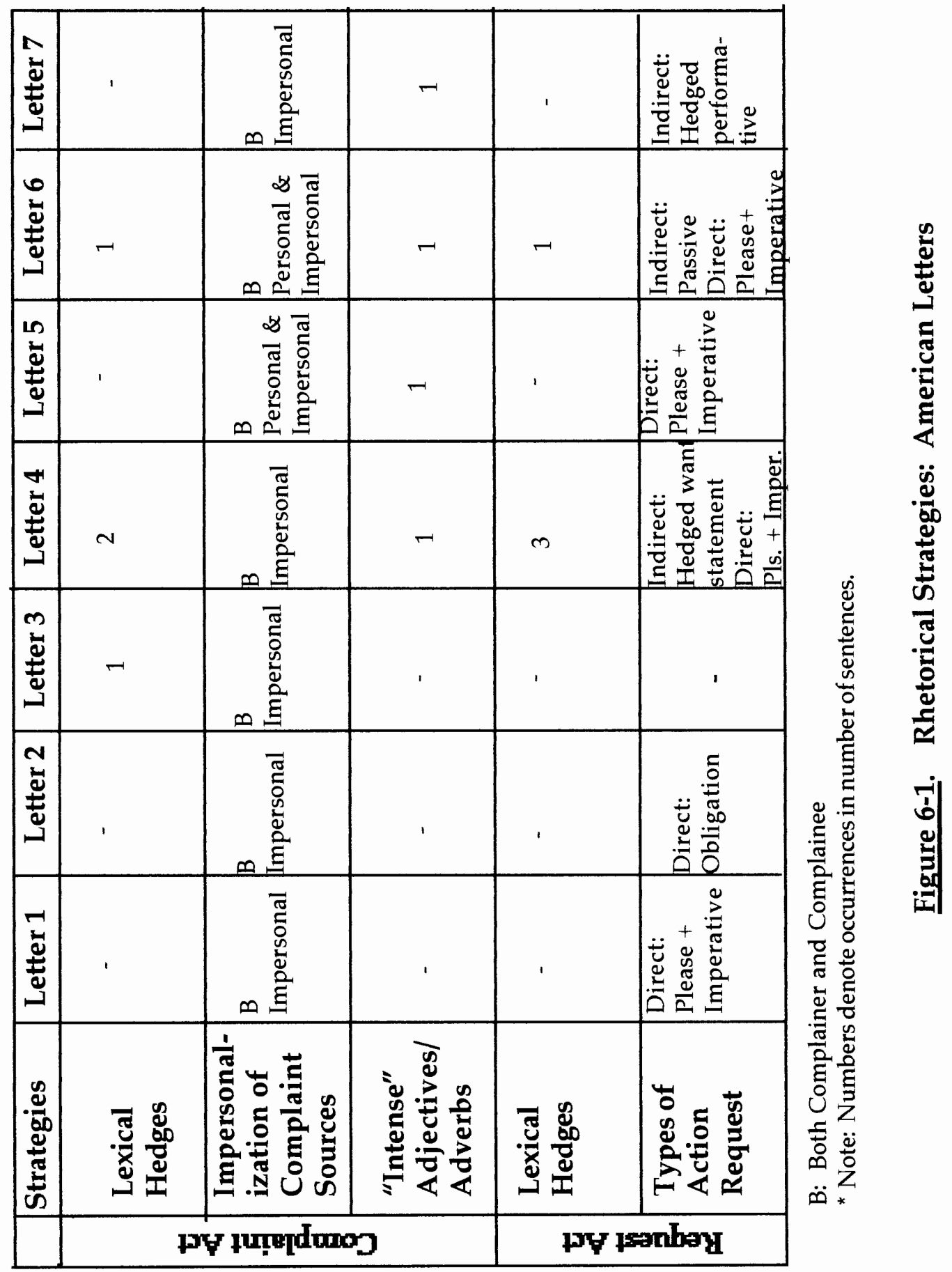




\begin{tabular}{|c|c|c|c|c|c|}
\hline N & 1 & 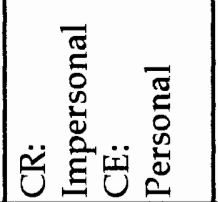 & - & ' & 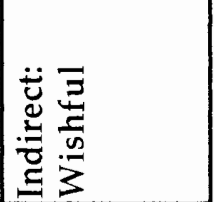 \\
\hline O & $r$ & 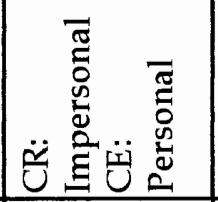 & - & ' & 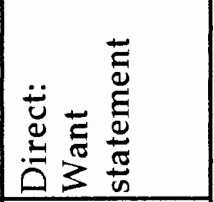 \\
\hline 战 & $N$ & 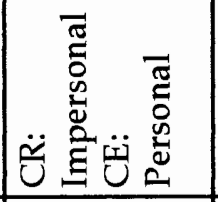 & & - & 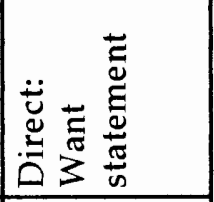 \\
\hline 苞 & ' & 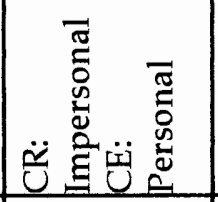 & 1 & ' & 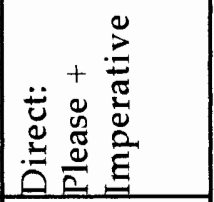 \\
\hline 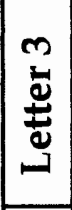 & ' & 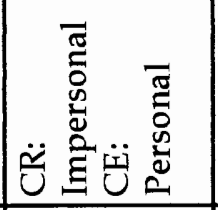 & ' & 1 & 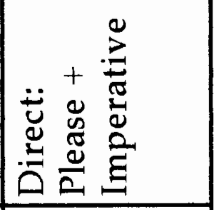 \\
\hline 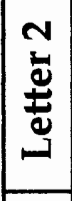 & - & 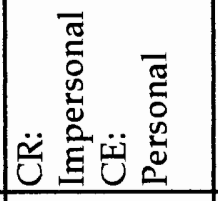 & - & ' & 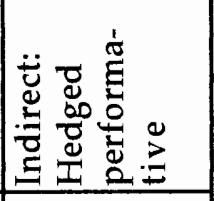 \\
\hline 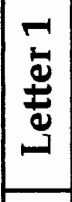 & $N$ & 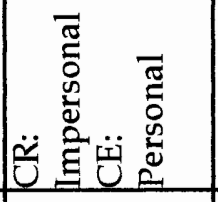 & $\nLeftarrow$ & & 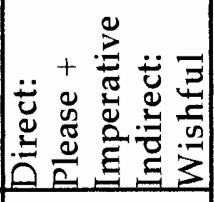 \\
\hline 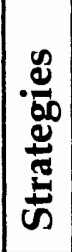 & שี & 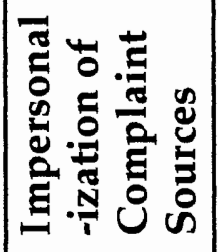 & 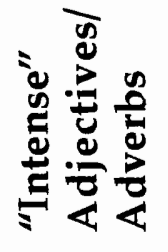 & 造 & 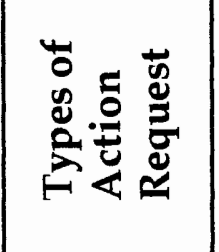 \\
\hline & \multicolumn{3}{|c|}{ 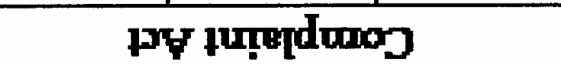 } & \multicolumn{2}{|c|}{ PY fonbay } \\
\hline
\end{tabular}



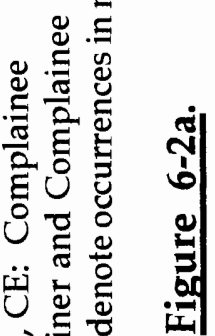
. 音 $\frac{\pi}{2}$ 을 U 岀禹象 


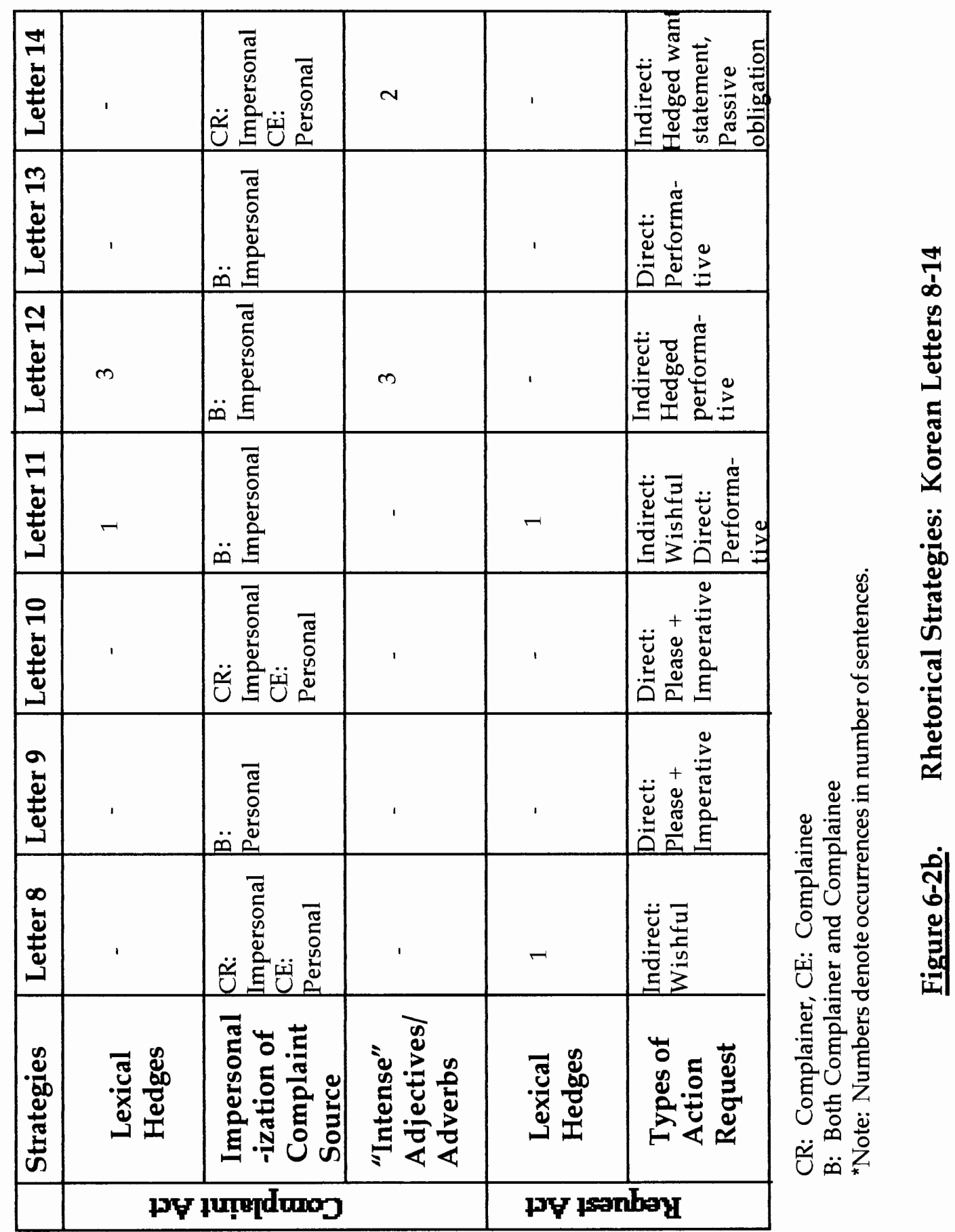




\section{Complaint Acts}

In this study, two important rhetorical styles (see Table 5) were explicit and implicit modes in business complaint letters. In terms of these discourse modes, complaint acts were analyzed using the list of rhetorical strategies that appear in Figures 6-1, 6-2a, and 6-2b, and are presented in the following discussion.

1. Lexical Hedges

Hedging words and phrases were evaluated in terms of occurrences and functions. In terms of occurrences, the percentage of letters containing lexical hedges was higher in American letters than in Korean letters: hedging expressions in complaint acts appeared in 4 out of 7 American letters (57\%) and in 6 out of 14 Korean letters $(42.8 \%)$.

Table 13.

Functional Categories of Hedges Used in Complaint Acts (Adapted from Salager-Meyer, 1994)

Functions $\quad$ American $\quad$ Korean

Shields

could be (1)

appear (1)

does not seem to (1) would be taken (1) may not (1) seem to be (1)

Approximators

some (1)

some (6)

somewhat (1)

( ): Number of occurrences 
As Table 13 shows, the two functional categories are "shields" and “approximators" (Salager-Meyer, 1994). Shields include all modal verbs, semi-auxiliaries such as "to appear," and probability adverbs such as "probably." Approximators include expressions of "rounders" of quantity or degree such as "somewhat." In both letter groups, major differences were found in both categories of functional categorization. In the American letters, shields were more prevalent than approximators: out of 4 total hedges, only one was an approximator. On the other hand, in the Korean letters the approximators were more prevalent than the shields: out of 10 total, only three were shields. This result indicates that Korean letters tend to heavily depend on "rounders" which "serve to make things vague" (Salager-Meyer, 1994, p. 154).

Generally, hedging devices in the American letters were used to soften the negative aspect of the message in business complaints; thus, hedging devices delivered the complaint act in an implicit mode. For example:

1) This could be a problem in that ...

2) XXX does not seem to be accommodating us as we feel ...

3) It appears a discrepancy exists.

In these American examples, hedges are used for deliberate purposes such as softening the statement of complaint and/or avoiding placing the blame directly on the reader by choosing particular hedges that allow the 
possibility of complainer error. The writer is "shielding" the reader from the direct fault. Due to this function of shields, the use of hedges in American letters helps the complaint discourse mode to be implicit.

However, the most often used hedging device in the complaint act in the Korean letters was "some":

(4) We are very surprised to receive some document from ...

(5) so we have some problem to...

(6) we think some of points are relevant ...

(7) we find against our expectation some of important transmittals...

(8) but it is some different total amount ...

These Korean examples illustrate a different aspect of hedging devices: the writers use the hedging expression some when presenting objective, factual problems instead of directly, clearly stating the problem. The Korean writers use "rounders," writing "around" what they mean instead of stating it specifically. Therefore, these hedging devices convey meaning in the complaint act in a vague, ambiguous mode rather than in an implicit mode. While Korean writers might attempt to be indirect or implicit regarding the complaint, using the hedge "some," their linguistic choice leads to indirectness which could make the business discourse vague and the complainer seem to be unclear as to the complaint. 
In terms of rhetorical style, hedges in American letters make the complaint act implicit, yet the message is still clear. In the domain of business discourse, this "pragmatic clarity" (Connor et al., 1995, p. 470) is an important feature when complaining. In Korean letters the degree of this "pragmatic clarity" is considerably lower, making the complaint act appear vague.

\section{Impersonalization of Complaint Sources}

One of the most striking differences in the Complaint Act category between American and Korean business letters is in the impersonalization of complaint sources (see Table 4).

Table 14.

Rhetorical Strategies for Complaint Sources

\begin{tabular}{lcc}
\hline & $\begin{array}{c}\text { American } \\
\mathrm{n}=7\end{array}$ & $\begin{array}{l}\text { Korean } \\
\mathrm{n}=14\end{array}$ \\
\hline Complaint sources & No. of letters & No. of letters \\
\hline 1) Impersonalization of both CR/CE & 5 & 3 \\
$\begin{array}{l}\text { 2) Mixed use of impersonalization } \\
\text { and personalization for both CR/CE }\end{array}$ & 2 & - \\
$\begin{array}{l}\text { 3) Impersonalization of CR and } \\
\text { personalization of CE }\end{array}$ & - & 10 \\
4) Personalization of both CR/CE & - & 1 \\
\hline
\end{tabular}

CR: Complainer, CE: Complainee

As Table 14 shows, 5 out of 7 American letters included impersonalization of 
both the complainer (CR) and complainee (CE) by using "we," "company name," or passive sentence structures; the remaining 2 American letters appeared to use mixed strategies of impersonalization and personalization. By contrast, only 3 out of 14 Korean letters included impersonalization of both complaint sources, whereas there were 10 letters in which the CR was impersonalized and CE was personalized. Finally, in the one remaining Korean letter, the CR and CE were both personalized.

In the following four examples of Korean strategies for complaint sources, sentence (9) is an example of personalization of both CR and CE, and the remaining three sentences (10-12) are examples of impersonalization of CR and personalizataion of CE:

(9) You should have discussed this matter beforehand with me ...

(10) In spite of our requests, we don't have any clear answer from you ...

(11) XXX [complaining company name] think you may not pay your attention ...

(12) Since you are lingering ..., we can not ...

Example (9) represents an extreme accusational rhetorical strategy by directly indicting the CE by referring to him/her as "you" instead of addressing the complaint to the company. Also in this example, the complainer is referred to as "me" instead of "my company" or "us." The remaining three examples (10-12) illustrate the most common types of complaint sources which are a mixture of $\mathrm{CR}$ impersonalization and $\mathrm{CE}$ personalization. These examples illustrate that impersonalization of the CR 
has the effect of taking the complainer out of the problem situation and personalization of $\mathrm{CE}$ has the effect of focusing the problem on the complainee. As a result, by objectifying only the complainer and identifying the CE as a person instead of the company, the CE is more explicitly identified in complaint acts in Korean business letters.

Compared to Korean letters, in most American letters both the CR and CE were hidden in the complaint act by impersonalization strategies for complaint sources. Also, personalization of both the CR and CE did not occur at all in American letters. In terms of rhetorical style, these results illustrate that American letters tend to be implicit in accusation of both complaint sources, whereas in Korean letters accusations tend to be implicit regarding the complainer, explicitly identifying or accusing the complainee within the complaint context.

\section{3. "Intense" Adjectives/Adverbs}

American letters used a greater percentage of "intense" adjectives/adverbs than Korean letters: this rhetorical strategy was found in 4 out of 7 American letters (57.1\%) and 6 out of 14 Korean letters (42.8\%). Although these strategies were used in a larger number of American letters, they occurred more often in fewer Korean letters. Even though "intense" adjectives/adverbs occurred in more American letters, the number of occurrences within each letter was usually limited to one as seen in Figure 
6-1. Unlike the American letters, Korean letters contained multiple occurrences of "intense" adjectives/adverbs within several letters (see Figures 6-2a and 6-2b). The use of multiple personal adjectives/adverbs within one letter gives an impression that Korean letters tend to show more personal, emotional feelings about the business problems.

As “attitude markers," (Vande Kopple, 1985, p. 85), "intense” adjectives/adverbs help to ensure that the message is conveying the writer's personal attitudes or feelings toward the problem situation. Consider the following American letter examples:

(13) XXX has not dealt honorably with ...

(14) We entered this order with good faith and ... that they would be honorable and trustworthy.

(15) We acted in good faith and assumed that XXX would do likewise.

Generally, the American "intense" adjectives/adverbs in these examples suggest an ethical approach by using words such as "good faith," "honorable," and "trustworthy." Even though "intense" adjectives/adverbs themselves convey the writers' attitudes or feelings in an explicit mode, the writers' points are implicit because they are making an implication questioning the integrity of the complainee. Also, the writers' emotional feelings such as "dissatisfaction" or "unhappiness" are implied within these implications. Overall, adjectives and adverbs do not relate to the complainer, but instead relate to the problem and/or complainee.

On the other hand, the Korean "intense" adjectives/adverbs tend to 
be directed toward the feelings of the complainer. For example,

(16) It seems to be very regrettable case for us.

(17) Unfortunately, we did not receive your ...

(18) We are so much concerning...

(19) XXX is much sorry to hear...

(20) We are very surprised to receive...

(21) We are very anxious for schedule impact and ... very seriously.

First, most Korean examples contain amplifiers such as "so much" and "very" which intensify the emotional tone. However, there are no occurrences of amplifiers in American letters; this omission of amplifiers shows that American writers are more controlled with their personal feelings. Second, the Korean "intense" adjectives/adverbs in these examples suggest an emotional approach by using words like "regrettable," "sorry" and "unfortunately." These words describe the writers' emotion and relate them to the complainer instead of the problem or complainee; therefore, the writers' personal feelings are explicit and do not require any further interpretation by the reader.

According to the analysis results, the use of "intense" adjectives/adverbs is an explicit mode of rhetorical style. Although both letter groups contained this rhetorical strategy in their complaint acts, its effects are different in the two groups of letters. In American letters this explicit strategy is used implicitly because the conveyed complaint messages are strong, but serious implications are embedded within the "intense" adjectives/adverbs. In Korean letters this strategy is not at all used 
implicitly because the feelings of the complainer are clear and explicitly revealed at the surface, with nothing implied toward the reader. Also, compared to American letters, the conveyed messages could be weaker because the writers' emotional states take precedence over the problem. In the domain of business discourse, the Korean rhetorical strategy of expressing personal feelings has the potential to make professional business complaint discourse more emotional and less formal.

\section{Request Acts}

Request acts included two rhetorical strategies: Lexical hedges and Types of action requests. Request acts were analyzed in terms of implicit and explicit modes of rhetorical style, and are presented in the following discussion.

\section{Lexical Hedges}

In request acts, hedging strategies appeared in 2 out of 7 American letters and 3 out of 14 Korean letters; thus, the difference in percentage of letters containing this rhetorical linguistic element was minimal: American 28.5\%; Korean 21.4\%. 


\section{Table 15}

Functional Categories of Hedges Used in Request Acts

(Adapted from Salager-Meyer, 1994)

\begin{tabular}{lll}
\hline Functions & American & Korean \\
\hline Shields & $\begin{array}{l}\text { may (2) } \\
\text { probably (1) } \\
\text { perhaps (1) }\end{array}$
\end{tabular}

Approximators

some (2)

something (1)

(): Number of occurrences

In terms of usage, differences in the request act category were similar to differences in the complaint act category: in both complaint and request acts, the functional categorization of most American hedges was shields, whereas most Korean hedges were approximators (see Tables 13 and 15).

Lexical hedges in request acts tend to produce different effects in American and Korean letters. For example, American hedging devices are intended to be polite leaving room for both reader choices and writer error:

(22) any assistance you may give us ...

(23) do contact us with any question you may have...

(24) If we can get the rate . ., we can probably get it done.

(25) If we could ..., perhaps they would match ...

In examples (22) and (23), hedging devices tend to deliver the request acts in a polite manner, and in examples (24) and (25), hedging adverbials suggest the "probability" of the "open-endedness" of resolution; in both 
occasions, the writers' voices are toned down. Therefore, American

hedging strategies can be characterized by expressions of "politeness" and "probability" to convey the request acts in an implicit mode.

On the other hand, while Korean hedging devices are intended to be polite, they often made the request message ambiguous. For example:

(26) also we want to do ... if we require something after discussion of our import agent.

(27) Anyway we hope to receive some information ...

(28) Besides, we have not yet received some drawings . . .

In these Korean examples, adverbial hedges suggest vague information as to what action is to be taken; thus Korean hedging strategies can be characterized by "vagueness" in request acts as well as in complaint acts.

Although the hedging strategy itself tends to create the implicit discourse mode, this effect appears only in American letters because Korean letters heavily depend on "approximators" or "rounders" that function to make the request act obscure (Salager-Meyer, 1994, p. 154). This result shows that in American letters the hedging strategy works to make the request implicit, while in Korean letters the hedges tend to make the message ambiguous.

2. Types of Action Requests

In American letters, the use of direct and indirect action requests was 
not unlike that of Korean letters. Direct action requests were used approximately $60 \%$ of the time in both sets of letters, and indirect action requests were used approximately $40 \%$; thus, in both letter groups the percentage of direct action request usage was similar, although it was slightly higher in the American letters as shown in Table 16.

Table 16

Types for Action Requests

\begin{tabular}{lll}
\hline & $\begin{array}{l}\text { American } \\
\mathrm{n}=7\end{array}$ & $\begin{array}{l}\text { Korean } \\
\mathrm{n}=14\end{array}$ \\
\hline Types of action requests & No. of occurrences & No. of occurrences \\
\hline $\begin{array}{l}\text { 1) Direct action request: } \\
\text { a) Imperative }\end{array}$ & - & - \\
b) Please + Imperative & 4 & 7 \\
c) Obligation & 1 & 1 \\
d) Performative & & 2 \\
e) Want statement & & $12=60 \%$ \\
\hline & $5=63 \%$ & - \\
\hline 2) Indirect action request & - & 5 \\
a) Suggestive & - & - \\
b) Wishful & & 1 \\
c) Passive obligation & 1 & - \\
d) Hedged performative & 1 & $8=40 \%$ \\
e) Hedged want statement & 1 & $20=100 \%$ \\
\hline & $3=37 \%$ & \\
\hline
\end{tabular}

In both American and Korean letter groups, several letters included both direct and indirect request strategies, so the number of occurrences does not match the number of letters, and in one American letter, a request act 
was not present at all.

In the direct type of action requests, "Please + imperative" structure is the most frequent type in both letter groups. For example,

(29) Please advise us as soon as possible because ...

(30) Please resolve this matter honorable by sending . . .

(31) Please let us know ...

(32) Please review with your people and advise ...

(33) Please resolve the outstanding order right now.

(34) Please settle the open invoice soon.

(35) Please advise us by fax.

(36) Please urgently investigate ... and advise...

In the above, statements (29-32) illustrate American examples and (33-36) illustrate Korean examples. In both letter groups, this type of action request appeared approximately half the time as a restatement of request because it came after the primary or main request acts.

In the indirect types of action requests, Korean letters showed a preference for "wishful" requests. For example,

(37) We hope you can make a replacement order for this ... (wishful) (38) XXX wishes that ZZZ provide the Block Diagrams ... (wishful) (39) We hope the following matter can be released ... (wishful)

From the rhetorical point of view, these examples illustrate that the writers' request acts are not declaratory, but anticipatory. To American readers, the verbs "hope" and "wish" seem to diminish the requests for action; the complainer seems to be unsure whether or not the complainee can or will 
comply. For instance, in (37) the writer could say "Please make a replacement order ..." instead of "We hope you can make a replacement order ...". The declaration would make it clear to the reader that the writer definitely expects results.

Unlike the Korean letters, the American letters contained no "wishful" type of requests at all, and regarding indirect request, American letters showed no specific preference for request types. The following are examples of American indirect action requests:

(40) I would be willing to go to different lines ... (hedged want) (41) We would like to request your ... (hedged performative) (42) Any assistance you may give us will be appreciated. (passive)

In examples (40) and (41), although the requests are indirect because they are hedged, they are still declaratory and assertive because the main verbs express the writers' want, calling for a specific action such as "go" and "request." Example (42) is not assertive, but still declaratory.

In both sets of letters the percentage of indirect action request usage was similar, although it was slightly lower in the American letters (see Table 16) while the result of the analysis showed that the degree of indirectness varied considerably. In American letters, the indirect action requests were declaratory; 2 out of 3 of the above examples are actually direct action requests with hedges added making it indirect. In Korean letters, the majority of indirect action requests (5 out of 8 examples) were 
wishful or hopeful instead of declaratory. In terms of rhetorical style, Korean business letters tend to be more conditional, while American letters tend to be more assertive.

Finally, purely "imperative" and "suggestive" types of action requests were not found in either American or Korean letters. This result seems to indicate that writers tend to avoid extremely direct or extremely indirect forms in business request acts.

\section{Summary of Rhetorical Style Patterns}

Table 17

The Style of Rhetorical Strategies

\begin{tabular}{lll}
\hline Rhetorical Strategies & American & Korean \\
\hline $\begin{array}{l}\text { Complaint Act } \\
\text { 1) Lexical Hedges }\end{array}$ & Implicit & Vague \\
$\begin{array}{rll}\text { 2) Complaint Sources } \\
\text { a) Complainer } \\
\text { b) Complainee }\end{array}$ & $\begin{array}{l}\text { Implicit } \\
\text { Implicit }\end{array}$ & $\begin{array}{l}\text { Implicit } \\
\text { Explicit }\end{array}$ \\
3) “Intense" Adj./Adv. & Implicit & Explicit \\
& & \\
\hline Request Act & & \\
1) Lexical Hedges & Implicit & Vague \\
2) Action Requests & Explicit & Explicit \\
& $\&$ Implicit & $\&$ Implicit \\
\hline
\end{tabular}

Regarding rhetorical style patterns, the American letters used implicit strategies consistently except in the action request where the 
strategy needed to be explicit. This made American writers' style seem controlled. On the other hand, Korean letters could not be categorized as either explicit or implicit because Korean writers were not consistent within rhetorical strategies. Rhetorical strategies in complaint acts of American letters were consistently implicit, whereas the strategies in Korean letters varied from vague to implicit to explicit. Within the complaint act, the consistent implicit style made the message in American letters seem polite, deliberate and non-accusatory, while the variations of style made the message in Korean letters seem vague, emotional, and accusatory to the complainee. However, regarding action requests in both groups of letters, explicit rhetorical style was used more frequently than implicit rhetorical style.

Overall, the lack of uniformity in either explicit or implicit style within a Korean letter leads to confusion of the intended message and a more emotional tone, unlike the American letters, which contained a consistent rhetorical style, which leads to clear presentation of the message and a more controlled tone. 


\section{CHAPTER V \\ CONCLUSION}

\section{Discussion of Research Questions}

Focusing on the genre of business fax letters of complaint, the purpose of this study was to find out if Korean and American business people use different rhetorical patterns in business writing, and if so, how these patterns differ. Specifically, this study examined rhetorical organization and style patterns of Korean and American business letter writing in English to determine differences.

\section{Research Question 1: In rhetorical organization, are there any} differences in the way Korean and American business people organize the business complaint message? If so, how can such differences be characterized?

In business complaint letters, significant differences were observed at the rhetorical level of organization between Korean and American business people. First, when analyzing the presence of meaning components, the results showed that in terms of word count in Categories I, II, and III which were considered major elements of direct development, American letters were considered more direct in organizational pattern 
than Korean letters (see Table 8 and Figure 3). Second, the results of the sequential order analysis (of meaning components) showed a significant difference between the two letter groups in general "move" patterns (see Figures 4-1, 4-2a, 4-2b, and 5). The American "standard" move pattern consisted of a sequential arrangement of meaning categories: Category I Category II - Category III and sometimes included an optional move, Category V. On the other hand, the Korean "standard" move pattern consisted of a non-sequential arrangement of meaning categories: Category II - Category I - Category III - Category V and sometimes the optional move, Category V was placed before Category II. Also, in the American letter group the majority of letters (5 out of 7 ) exactly matched the American model; in the Korean letter group only 4 out of 14 followed the American standard model, and the rest of the letters followed either the Korean standard model or variant forms of the Korean standard model.

These differences suggest that Korean and American business people use different approaches in organizing the business complaint message. While American business writers tend to use direct and deductive development patterns, Korean writers tend to use patterns that are indirect and inductive. In American letters, the main idea or problem (Category I) is presented first, then explanatory details (Category II) follow in a tightly related manner. This immediate statement of the problem helps the reader to understand the writer's point clearly, and the consecutive explanations 
guide the reader in following the writer's logic; in this sense, the reader need not infer what the problem is or what the writer wants. Also, buffers which occur infrequently, come at the end of the complaint discourse so they seldom interrupt the direct development organization of the point. Based on these features, the American rhetorical pattern of organizing the business complaint message can be characterized as "direct" or "linear."

By contrast, in most Korean letters the sequential order of "moves" differs from that of the American letters. Relevant information about the problem (Category II) is often provided first before stating the problem (Category I). This choice of rhetorical organization seems to delay the identification of the problem to the readers who are not familiar with this pattern, and this delay often requires the reader to read a lot of details, sometimes relevant and sometimes not, before the reader is told what the problem is. Also, the use of buffers in the opening and middle paragraphs contributes to delaying the immediate statement of the problem and interrupts the sequential flow of "moves" (I - II - III) which make the message direct in complaint discourse. In addition, when actually stating the specific problem, presenting relevant information and/or action requests, "Lack of Specificity" occurs causing an omission of details essential to following the writer's logic, and this gives the reader the impression of reading unclear and ambiguous text. In this sense, the reader is often required to guess or interpret what the exact problem is and what 
the writer wants done about it. Based on these features, the Korean rhetorical pattern of organizing the business complaint message can be characterized as "indirect" or "non-linear."

\section{Research Question 2: In rhetorical organization, are there any differences in the way Korean and American business people use connectives? If so, how do the differences affect the organizational pattern?}

A comparison on the use of connectives showed differences between the two business groups. Interestingly, the analysis showed that in terms of frequency and variety, Korean letters contained a larger number and greater variety of connectives than American letters (see Table 12). However, in terms of appropriate use, some connectives in Korean letters were overused or misused, while no connectives were used inappropriately in American letters. For example, the analysis showed that the two Korean "favorite" connectives, anyway (subject changer) and now (tense changer) were used inappropriately; instead of creating smooth and coherent transitions, these connectives seemed to detract from the logical relationships between paragraphs, making the text organization seem incoherent. Such use of connectives in Korean letters might indicate that Korean writers have difficulties using connectives appropriately, or use connectives differently from American writers. At the rhetorical level of organization, this result indicates that Koreans' use of connectives is one 
factor contributing to digressive development in Korean business letters.

In contrast, American texts were more consistently organized and directly developed even though they contained fewer connectives. This result suggests that compared to their counterparts, American writers are less dependent on connectives in discourse organization, and they are more skillful at making coherent links in transitions. Also, this result might indicate that connectives are not always essential to coherent text organization; however, the inappropriate use of connectives contributes to incoherent or digressive text organization.

Research Question 3: In complaint acts, are there any differences in the way Korean and American business people use rhetorical strategies (lexical hedges, impersonalization of complaint sources, and "intense" adjectives/adverbs)? If so, how do the differences affect the rhetorical style patterns?

Differences were observed in the use of the above three rhetorical strategies between Korean and American business people in business complaint acts.

Concerning lexical hedges in complaint acts, a major difference was found in the functional categorization for hedges used in the two letter groups (see Table 13). The results showed that among hedges used in American letters, the category "shields" (e.g., could be, appear, seem to) was prevalent, whereas in Korean letters, "approximators" or "rounders" (e.g., some, somewhat) were prevalent. Based on their primary rhetorical 
functions, the "shields" in American letters served to soften the statement of complaint by "shielding" the reader from direct "fault." On the other hand, the "rounders" in Korean letters primarily functioned to make the writer's complaint point vague by avoiding specificity when presenting objective, factual problems.

From a rhetorical style standpoint, these results suggest that hedging strategies in American letters help the writer to deliver the negative aspect of the complaint message in an implicit mode, but in Korean letters the writer's choice of hedges produces vague statements rather than an implied message. In business complaint discourse, although the implicit mode is used to avoid a direct complaint, it should not be confused with vagueness because the writer still needs to deliver the intended message clearly to avoid misinterpretation. This sense of implicitness or "pragmatic clarity" (Connor et al., 1995, p. 470) does not appear in Korean letters.

Differences were also found in the use of impersonalization strategies for complaint sources (see Table 14). In most American letters (5 out of 7) both the complainer and complainee were "hidden" in the complaint act by impersonalization strategies. On the other hand, in most Korean letters (10 out of 14) only the complainer was "hidden" by impersonalization, and the complainee was directly indicated by personalization. In terms of rhetorical style, these results indicate that American writers tend to be implicit in accusation of both complaint sources; even though there is a 
complaint, any direct fault has been removed from both parties. However, Korean writers tend to be explicit presenting only the complainee to be at fault, removing blame and shielding the complainer through impersonalization.

Finally, the strategy of "intense" adjectives/adverbs was also used differently between the two letter groups in complaint acts. The analysis showed that even though "intense" adjectives/adverbs themselves convey the writer's personal attitude or feelings in an explicit mode, the ways in which American and Korean writers used this rhetorical strategy were different. In American letters, personal adjectives and adverbs were not generally related to the complainer, but instead related to the problem and/or complainee, making the writer's personal feelings implicit. By contrast, in Korean letters these linguistic devices tended to be related to the complainer's own feelings, intensifying the writer's tone, making it seem more emotional.

From the rhetorical style standpoint, the use of "intense" (personal) adjectives/adverbs is an explicit mode of delivering the complaint message. However, at the functional level different usage creates different modes of rhetorical style: in Korean letters this strategy is used to deliver the writer's complaint act in an explicit mode, whereas in American letters this strategy is used to deliver the writer's complaint act in an implicit mode. 
Overall, differences found in the use of hedges, impersonalization of complaint sources, and "intense" adjectives and adverbs show that the styles of writing in the two letter groups vary significantly. In American letters, the use of these rhetorical strategies helps the writer's style to be consistently implicit when making business complaints; in other words, the writer's complaint message is delivered implicitly in a clear, formal manner. By contrast, the use of these rhetorical strategies in the Korean letters varies from vague to implicit to explicit in modes of style, and these variations in style modes within a letter create an ambiguity about the writer's attitude and/or point of complaint, although the complaint act itself is apparent but less formal. It could be possible that Korean writers were trying to create an implicit mode like American writers; however, due to their different use of the above three rhetorical strategies for complaint acts, the Korean writers' intentions are not delivered clearly.

Research Question 4: In request acts, are there any differences in the way Korean and American business people use rhetorical strategies (lexical hedges and types of action requests)? If so, how do the differences affect the rhetorical style patterns?

A significant difference was observed in the use of lexical hedges in request acts, while both similarities and differences were observed in the use of types of action requests.

In regard to lexical hedges, the differences observed in complaint 
acts also appeared in request acts: the functional categorization of most American hedges was "shields," whereas most Korean hedges were "approximators" or "rounders" (see Tables 13 and 15). In American letters, hedging strategies were used to maintain a polite tone by leaving room for both reader choice and writer error. In Korean letters, on the other hand, hedging strategies were used to make the request acts indirect, making the request for action an ambiguous suggestion. Thus, the implicit discourse mode is effectively created in American letters, but this mode is not created in Korean letters; in other words, the request act in American letters is more clear.

In action request strategies, the results showed that in both letter groups the use of direct action requests was higher (approximately 60\%) than the use of indirect action requests (approximately 40\%) (see Table 16). Also, among the direct type of action requests the "Please + imperative" structure appeared to be the most frequent type in both letter groups. Regarding the indirect types of action requests, a "wishful" type of request was prevalent in Korean letters, and this request for action was not emphatic therefore making the writer's request "doubtful." On the other hand, American indirect action requests were declaratory with the use of hedges calling for a specific action. This difference might indicate that stylistically Koreans are more indirect than Americans when requesting action. 
Overall, in both letter groups, the choices and usage of lexical hedges and action requests affect the way in which the request act is perceived. The request act in American letters is clear in both explicit and implicit modes; however, in Korean letters implicitness seems to create hesitation or reluctance and undermines the clear request for action.

\section{Conclusions}

From this study, the researcher draws the following conclusions about rhetorical differences in English business fax letter writing between Korean and American business people:

1. In rhetorical organization patterns, English fax letters written by American business are "direct" or "linear," and those written by Korean business people are "indirect" or "non-linear." Therefore, this particular conclusion supports the findings of several studies of contrastive rhetoric such as Kaplan (1966, 1972), Hinds (1987, 1990), and Norton (1987) within the academic setting.

2. In rhetorical style patterns of complaint acts, American business people's rhetorical styles are consistently implicit in the use of lexical hedges, impersonalization, and "intense" adjectives/adverbs. This consistent, implicit mode gives the American letters a clear neutral tone. Korean business people's rhetorical styles, on the other hand, are not consistent. Korean business people's use of lexical hedges tends to 
create "ambiguity," while their use of the impersonalization strategy makes the complaint act itself explicit. Also, their use of "intense" adjective/adverbs is explicit and gives the Korean letters an emotional tone.

3. In rhetorical style patterns of request acts, both Korean and American business people use direct and indirect strategies making their requests acts both explicit and implicit. The difference lies in clarity; in implicit mode, American request acts are more clear.

The conclusions of this study suggest that although English is used as the "common" language within the international business community, at the rhetorical level differences exist between Korean and American speakers of English.

Several things might account for the differences in rhetorical patterns between the two groups. In Korea, learners are primarily taught English at the micro- or sentence level; this could make it difficult for them to function in L2 business letter writing at the macro- or discourse level. Also, Koreans are seldom explicitly taught that English rhetoric is more linear and deductive, and carries writer responsibility. Similarly, Korean L2 writers might attempt to follow the American models they have learned, but it is difficult for them to apply sentence level strategies at the discourse level. Finally, L1 (Korean) cultural rhetorical patterns which are 
considered indirect and inductive, and which carry reader responsibility might overlap into L2 business letter writing. Within the scope of this present study, whether or not such differences are solely culturally related has not been dealt with; however, the results of this study can be considered a starting point for investigating the nature of such differences in the L2 writings of Korean and American business people.

Furthermore, based on this research, it is important to recognize that the differences in rhetorical patterns can be a source of potential miscommunication. With respect to business complaint letter writing, a clear awareness regarding a counterpart's rhetorical pattern (i.e., what style is appropriate, and in what order the ideas are organized) is important because the differences can be problematic in effective communication and consequently can affect business relationships. If one group's rhetorical expectation is violated, this may cause confusion to the reader and lead to misinterpretation. If American business people become aware of Korean business people's rhetoric in L2 business letter writing, they can be more understanding toward "foreignness" (Eggington \& Ricento, 1983). Also, it is important that Korean business people become aware that their rhetorical approach in L2 business complaint letter writing is different from American business people's rhetorical approach, and thus may affect clear communication. 


\section{Pedagogical Implications}

The findings of this contrastive rhetorical pattern analysis suggest several pedagogical implications for Korean learners of English, particularly English for business purposes.

First, consideration of organization and style at the rhetorical level is important in L2 business letter writing. While the discussed differences in rhetorical patterns may not cause serious communication breakdowns in business settings, they certainly affect clear and effective communication between American and Korean business people. For example, if American business people are used to certain rhetorical patterns as they appear in their L1 business letter writing, then they are likely to expect the same patterns when reading business letters, even though the letters are the product of a different culture. As Mauranen (1993) points out, rhetorical patterns used in writing are the same ones expected when reading (p. 17). Therefore, when Korean writers use a different rhetorical pattern, American readers' expectations are violated, and this may cause problems with understanding, making the Korean writer's different rhetorical patterns and strategies less appealing and less convincing. Thus, it is necessary to consider other culture's stylistic strategies and expectations of rhetorical level organization in L2 business letter writing.

Second, use of language should be taught at the functional level. The rhetorical pattern analysis of this study demonstrates that the way Korean 
business people use linguistic devices (connectives, lexical hedges, or "intense" adjectives or adverbs) and structure sentences creates confusion and vagueness because their usage is often grammatically awkward and syntactically inappropriate. In many cases, their use or choice of linguistic devices seems to be the result of a lack of understanding of the functions of these devices within business contexts. Instead of a pedagogy that relies on fixed models of language form, Korean learners need to be taught the ways in which these linguistic devices function within a given discourse situation.

Third, even though it is necessary to shift Korean L2 writers' attention from mechanics to discourse level strategies, essential mechanics such as punctuation (e.g., comma, semicolon, colon) and paragraphing should also be taught at the functional level. While the inappropriate use of mechanics and paragraphing appears to be a sentence level difficulty, in actual written discourse their usage affects the clarity of the message and the organization of the text. The researcher's English language learning experience and the examination of the English business writing texts in Korea reveal that Korean learners are not taught how punctuation operates at the functional level and how paragraphing affects the text organization. Thus, many Korean learners are unable to apply mechanics and paragraphing effectively in different rhetorical situations. To enhance the Korean business writer's expertise, credibility, and professionalism, clear 
and explicit instruction on the correct usage of punctuation and paragraphing is essential.

Fourth, a brief examination of textbooks and handbooks used for business English in Korea suggests that they are not effective in teaching Korean learners to use the English language competently in L2 written business discourse. While general principles of L2 business letter writing are explicitly mentioned in Korean texts, the ways in which those principles function are ignored. Another element of writing competency ignored in Korean texts is a discussion of writing process. Because the pedagogy is based on modeling, the situational context is missing; thus, Korean learners have minimal opportunity to develop invention or revision strategies. This seems to indicate that compared to American texts, L2 business writing pedagogy is relatively undeveloped in Korean texts. Korean learners need to recognize writing as an active, progressive process rather than an imitative one.

Also, in order to strengthen the English language skills in written business discourse, it is important to recognize the actual needs of learners in the professional setting and to provide practical exercises within contexts so that they can transfer what they learn to actual business situations. Although many Korean companies provide additional training, until the handbooks and textbooks begin to address issues stated above, this additional training will only serve to reinforce the prevailing pedagogy. 
In conclusion, the findings of this study strongly suggest that awareness of rhetorical level differences in the English writings of Korean and American business people can be beneficial for both Koreans and Americans by facilitating clear and effective communication. As Beamer (1994) points out, awareness of the L2 rhetorical pattern is meaningful "because of its use" in business, not because one rhetorical pattern is better than another (p. 16).

\section{Limitations}

Some of the limitations of this study include a relatively small sample size and the difference in size of the two groups ( 7 American samples and 14 Korean samples) because of availability. These factors result in a low level of generalizability of the findings of this study.

In the procedure of data collection, the researcher and the researcher's representatives made contact at a company level instead of contacting individuals, and all names of persons and companies were deleted prior to the gathering of data in order to preserve confidentiality. Thus, the researcher did not know individual authors' identities or their native language, but only the nationality of their companies. For Korean samples, two native speaker informants reviewed the sample letters and excluded letters that both agreed were written by native speakers of American English; however, the researcher still could not be sure that all 
sample letters were solely written by native speakers of Korean. For the same reason, in American samples the researcher was not able to be sure that authors were all native speakers of American English even though they were working for American companies in the U.S. Also, there was no way to differentiate the gender of the writers.

In addition, when analyzing complaint letters, business contexts were missing. In other words, the researcher did not have any background information about the context in which the business complaint letters were sent and received. The researcher tried to get some background information through interviews, but this was not acceptable to the participating companies. Therefore, the researcher's analysis and interpretations had limitations in considering situational factors. Overall, these limitations are primarily related to the availability of samples. As St John (1996) points out, many companies consider their business correspondence confidential, and are reluctant to permit outsiders to look at their business correspondence and to give comprehensive situational explanations (p. 4).

Finally, the sample letters for this study were analyzed only by the researcher. As Virtanen (1995) points out, "different analysis provides us with different perspectives on the same text" (p. 545). This suggests that multiple analyses of the sample business letters are recommended in order to provide inter rater reliability. Thus, this research is lacking the inter 
rater perspective.

\section{Suggestions for Further Research}

Future research will be enhanced by broadening the study with a larger sample size. Also, with regard to L2 business letter writing, having the contexts of the letter available to the researcher will aid in a more accurate data analysis.

In addition, within the realm of cross-cultural business discourse, it is important to raise the issue of communication breakdowns in an actual business setting: Do differences in rhetorical patterns in the English writings of Korean and American business people affect cross-cultural communication? Further research might be initiated using interviews with both Korean and American business people to find out specifically if the rhetorical differences cause communication breakdowns in L2 business writing.

If the researcher is allowed more access to the company's business contexts and language training programs in Korea, the researcher can design an experimental study in which she presents small workshops to show rhetorical differences and strategical approaches, and look at how this training affects learner's L2 business letter writings. Also, the researcher can construct a survey questionnaire asking how American readers respond to Korean's L2 business letters before and after the workshop. 
Finally, this study contained a brief examination of textbooks and handbooks in relation to L2 business letter writing pedagogy. Focusing on education, another study might look more closely at Korean textbooks and pedagogy and the ways in which they influence Koreans' L2 business writing. Such a study might suggest ways to develop methods for teaching Korean learners to communicate effectively and clearly in business contexts. 


\section{REFERENCES}

Bar-Lev, Z. (1986). Discourse theory and "contrastive rhetoric." Discourse Process, 9 (2), 235-246.

Beamer, L. (1994). Teaching English business writing to Chinesespeaking business students. The Bulletin of the Association for Business Communication, 57(1), 12-18.

Blake, G., \& Bly, R. W. (1991). The elements of business writing. New York: Macmillan, Co.

Bovée, C., \& Thill, J. (1995). Business communication today (4th ed.). New York: McGraw-Hill, Inc.

Brown, P., \& Levinson, S. (1987). Politeness: Some universals in language usage. Cambridge: Cambridge University Press.

Connor, U. (1988). A contrastive study of persuasive business correspondence: American and Japanese. In S.J. Bruno (ed.), Global Implications for Business Communications: Theory, Technology, and Practice. 1988 Proceedings 53rd National and 15th International Convention of the Association for Business Communication (pp. 57-72). Houston, TX: School of Business and Public Administration, University of Houston

Connor, U., David, K. W., \& Rycker, C. (1995). Correctness and clarity in applying for overseas jobs: A cross-cultural analysis of US and Flemish applications. Text, $\underline{15}(4), 457-475$.

Eggington, W., \& Ricento, T. (1982). Discourse analysis as a pedagogical tool. Paper presented at the CATESOL State Conference, Sacramento, CA., Mar 13, 1982. (EDRS: ED 236938)

Ewald, H., \& Stine, D. (1983). Speech act theory and business communication conventions. The Journal of Business Communication, $\underline{20}(3), 13-25$.

Frank, J. (1990). Establishing reader involvement in transnational marketing communications: Relative focus on speech-like or written-like strategy. (EDRS: ED 334820)

Hagge, J., \& Kostelnick, C. (1989). Linguistic politeness in profecional prose: A discourse analysis of auditors' suggestion letters, with implications for business communication pedagogy. Written Communication, $\underline{6}(3), 312-339$. 

Longman.

Halliday, M. A. K., \& Hasan, R. (1976). Cohesion in English. London:

Harcourt, J., Krizan, A., \& Merrier, P. (1996). Business communication. Cincinnati, Ohio: South-Western Educational Publishing.

Harris, C. (1982). Certificate English usage. Hong Kong: Aristo Educational Press.

Hatch, E. (1992). Discourse and language education. Cambridge: Cambridge University Press.

Hinds, J. (1987). Reader versus writer responsibility: A new typology. In Ulla Connor and Robert B. Kaplan (eds.), Writing across languages: Analysis of L2 text (pp. 141-152). Addison-Wesley Publishing Company.

. (1990). Inductive, deductive, quasi-inductive: Expository writings in Japanese, Korean, Chinese, and Thai. In Ulla Connor and Ann M. Johns (eds.), Coherence in writing (pp. 89-109). Alexandria, VA: Teachers of English to Speakers of Other Languages, Inc.

Hinkel, E. (1994). Native and nonnative speakers' pragmatic interpretations of English texts. TESOL Quarterly, 28 (2), 353-376.

Jenkins, S., \& Hinds, J. (1987). Business letter writing: English, French, and Japanese. TESOL Quarterly, 21(2), 353-349. ?

$$
32+345^{\circ}
$$

Kachru, Y. (1995). Contrastive rhetoric in World Englishes. English Today, 11(1), 21-31.

Kaplan, R. (1966). Cultural thought patterns in inter-cultural education. Language Learning, $\underline{16}(1,2)$ 1-20. composition. TESOL Quarterly, $2(1), 10-16$. (1967). Contrastive rhetoric and the teaching of (1972). The anatomy of rhetoric: Prolegomena to a functional theory of rhetoric. Philadelphia: The Center for Curriculum Development Inc.

Kenna, P., \& Lacy, S. (1995). Business Korea: A practical guide to understanding South Korean business culture. Chicago, IL: Passport Books.

Kim, D. Y. (1993). 무역영엉 [Trade English]. Seoul: Shinyoungsa.

Kim, M. S., \& Bresnahan, M. (1994). A process model of request tactic evaluation. Discourse Process, $\underline{18}(3), 317-344$. 
Kong, S. Y., \& Jeon, J. H. (1996). Trade English. Changwon: Changwon National University Press.

Lakoff, G. (1973). Hedges: A study in meaning criteria and the logic of fuzzy concepts. Journal of Philosophical Logic, 2(4), 458-508.

Liebman, J. (1988). Contrastive rhetoric: Students as ethnographers. Journal of Basic Writing, $7(2), 6-27$.

Louhiala-Salminen, L. (1996). Business communication classroom vs reality: What should we teach today? English for Specific Purposes, 15(1), 37-51.

Maier, P. (1992). Politeness strategies in business letters by native and non-native English speakers. English for Specific Purposes, 11(3), 189-205.

Martin, J. E. (1991). Contrastive rhetoric: Implications of a revised approach to text. (EDRS: ED 329118)

Matalene, C. (1985). Contrastive rhetoric: An American writing teacher in China. College English, $\underline{47}(8), 789-808$.

Mauranen, A. (1993). Contrastive ESP rhetoric: Metatext in FinnishEnglish economics texts. English for Specific Purposes, 12(1), 3-22.

Mohan, B. A., \& Lo, W. A. (1985). Academic writing and Chinese students: Transfer and developmental factors. TESOL Quarterly, 19(3), 515-534.

Murphy, H., \& Hildebrandt, H. (1988). Effective business communications(5th ed.). New York: McGraw Hill.

Nakamura, H. (1996). 입문 무역영어 [Introduction to Trade English]. Seoul: Young Poong Book Store Co., Ltd.

Norton, R. F. (1987). A comparison of thinking and writing patterns in Korea and the United States. AFS Occasional Papers in Intercultural Learning No. 12. (EDRS: ED 290648)

Nunan, D. (1992). Research methods in language learning. Cambridge: Cambridge University Press.

Piotrowski, M. V. (1996). Effective business writing. New York: HarperPerennial.

Plung, D. L. (1980). Writing the persuasive business letter. The Journal of Business Communication, 17 (3), 45-49. 
Robinson, P. (1991). ESP today: A practitioner's guide. London: Prentice Hall.

Salager-Meyer, F. (1994). Hedging in medical discourse. English for Specific purposes, $\underline{13}(2), 149-170$.

Scott, J., \& Green, D. (1992). British perspectives on organizing badnews letters: Organizational patterns used by major U.K. Companies. The Bulletin of the Association for Business Communication, 55(1), 17-19.

Severino, C. (1993). The "doodles" in context: Qualifying claims about contrastive rhetoric. The Writing Center Journal, 14(1), 44-61.

Shishin, A. (1985). Rhetorical patterns in letters to the editor. Journal of the Aichi Institute of Technology 20.17-28. (EDRS: ED 288350)

Silva, T. (1993). Toward an understanding of the distinct nature of L2 writing: The ESL research and its implications. TESOL Quarterly, 27(4), 657-677.

Sims, B., \& Guice, S. (1992). Differences between business letters from native and non-native speakers of English. The Journal of Business Communication, 29(1), 23-39.

St John, M. J. (1996). Business in booming: Business English in the 1990s. English for Specific Purposes, 15 (1), 3-18.

Swales, J., \& Najjar, H. (1987). The writing of research article introductions. Written Communication, 4(2), 175-191.

Vande Kopple, W. J. (1985). Some exploratory discourse on metadiscourse. College Composition and Communication, 36 (1), 82-93.

Varner, I. (1988). A comparison of American and French business correspondence. The Journal of Business Communication, $\underline{25}(4), 55-65$.

Virtanen, T. (1995). Analyzing argumentative strategies: A reply to a complaint. In Warvik, B., S-K. Tanskanen \& R. Hiltunen (eds.), Organization in Discourse. Proceedings from the TURKU Conference. 1995. Anglicana Turkuenisa 14, 539-547.

Yli-Jokipii, H. (1991). Running against time and technology: Problems in empirical research into written business communication. In Communication and Discourse across Cultures and Language. AFinLa Yearbook 1991. (EDRS: ED 341276) 
Yoon, H. K. (1991). 무역영어 통신무 [Practical English correspondence for foreign trade]. Seoul: Hakil Publishing Co.

Yum, J. (1987). Korean philosophy and communication. In D. Lawrence Kincaid (ed.), Communication theory: Eastern and Western perspectives (pp. 71-86). San Diego, CA: Academic Press Inc.

(1988). The impact of Confucianism on international relationships and communication patterns in East Asia. Communication Monographs, $\underline{55}$ (3), 374-388. 
A PPENDICES

A INFORMED CONSENT FORM IN ENGLISH

B INFORMED CONSENT FORM IN KOREAN 


\section{INFORMED CONSENT FORM}

I agree to take part in this research project which Mi Young Park is doing to discover differences in rhetorical patterns between English fax letters of trade complaints or claims written by Korean and American business people.

I understand that the study involves the researcher reading the fax letters of trade complaints or claims in order to examine them rhetorically. I also understand all names of persons and companies should be deleted from the letters before giving them to the researcher's representative.

Mi Young Park's representative has explained to me that all private business information will be kept confidential. Also, I may not receive any direct benefit from taking part in this study, but my company's participation could help promote better communication between Korean and American business writing. Mi Young Park's representative has offered to answer any questions about this study and what I am expected to do. If he can not answer any questions, I may contact Mi Young Park at her expense to answer any questions I have.

I have read the above information and agree to take part in this study.

Date: Signature:

If you have any concerns or questions about this study, please contact the researcher, Mi Young Park at (0011) 503 497-9037, or contact the Chair of the Human Subjects Research Review Committee, Research and Sponsored Projects, 105 Nueberger Hall, Portland State University, (0011) 503 725-3417. 
동 의 서

나 (우리 회사) 는 박 미영의 연구 - 한국과 미국의 비지니스맨이 거래상의 고충이나 불만사항 등을 의논 하기 위해 서로 간에 주그받은 영문의 팩스 서신에 나타나는 언어학적인 특성에 대한 고찰 - 에 참여할 것을 동의합니다.

나는 이 논문의 연구자가 언어학적인 특성을 검토하기 위하여 내 (우리회사) 가 미국인 회사와의 사이에 거래상의 고충이나 불만 사항 등을 의논 하기 위해 서로 간에 주고받은 영문의 팩스 서신들을 읽는다는 것을 알고 있습니다. 또한 논문 자료 수집의 대리인에게 자료를 주기 전에 회사나 개인의 이름이 꼭 지워져야 한다는 것도 알고있습니다.

박 미영의 대리인은 나 (우리 회사)에게 업무상의 정보에 대하여 비밀이 보호된다는 것을 알려주었읍니다. 또한 나 (우리 회사)는 이 연구에 참여하여 직접적인 이익을 받지 못할 수도 있으나 나 (우리 회사)의 참여는 한미간 비지니스 서신의 교환에 있어서 보다 효과적인 의사소통을 위한 기여를 할 수 있을 것입니다. 박 미영의 대리인은 내가 하여야 할 일들과 이 연구에 관한 어떠한 질문에도 기꺼이 답변할 것을 알려 주었읍니다. 만약 에 대리인이 답변할 수 없는 경우에는 박 미영에게 수신인 부담으로 연락을 할 수 있읍니다.

나는 위의 내용을 읽었으며 이 연구에 참여할 것 을 동의합니다.

서명일 :

서명인 :

이 논문에 관한 기타 의 질문이 있으면 본인 박 미영 (전화 : 001-1-503-497-9037) 이나 포틀랜드 주립대학의 논문 인구넌보호 사정 위원회 (전화 : 001-1-503-725-3417) 로 문의 하여 주십시오. 